\title{
Life Study Scientific
}

Meeting January 2016:

Presentations

Presentations made at a Scientific Meeting

held at

The Royal College of Physicians

$14^{\text {th }}$ January 2016

EDITOR

Carol Dezateux 


\section{Acknowledgements}

This work was supported by the Economic and Social Research Council [Grant numbers ES/J007501/1, ES/L002507/1, ES/L002353/1, ES/L012871/1, ES/N007549/1]

Life Study Scientific Committee members:

Professor Peter Brocklehurst

Professor Simon Burgess

Professor Carol Dezateux

Professor Peter Elias

Professor Paul Elliott

Professor Alan Emond
Professor Hilary Graham

Professor Frank Kelly

Professor Kathleen Kiernan

Professor David Leon

Professor Diane Reay

Professor Anna Vignoles (chair)

ISSN 2398-1652. DOI: 10.14324/000.wp.1485679

URL: http://discovery.ucl.ac.uk/1485679/

\section{(c) $($ i) $(9)$}

Life Study Working Papers are licensed under a Creative Commons AttributionNonCommercial-NoDerivatives 4.0 International License 


\section{Update on sampling and recruitment in pregnancy}

\section{Carol Dezateux}

Life Study Scientific Meeting 14th January 2016 


\section{Background}

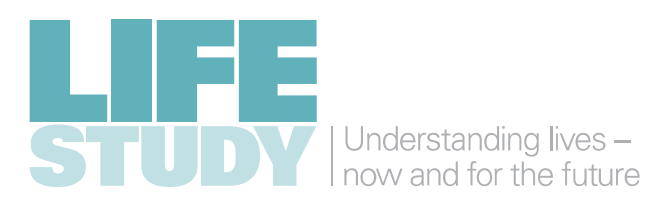

\section{Phase 1 (innovation phase): Jan 2014 to Oct 2017}

\section{Establish NHS and Biorepository Partnerships}

- Barking Havering Redbridge University Hospitals NHS Trust

- University Hospitals of Leicester NHS Trust

- Invitation to tender for Biorepository posted Sept 2014

- UK Biocentre selected as preferred bidder November 2014 Evaluate recruitment and innovation

- Recruitment in pregnancy in two NHS centres

- Retention at 6 and 12 months after birth

- Collection \& processing of innovative biosamples

- Innovative child development measures @6 \& 12 mos

This presentation

- What did we achieve?

- When was the Study closed?

- What challenges did we encounter?

- What have we learnt? 


\section{Recruitment in Innovation Phase}

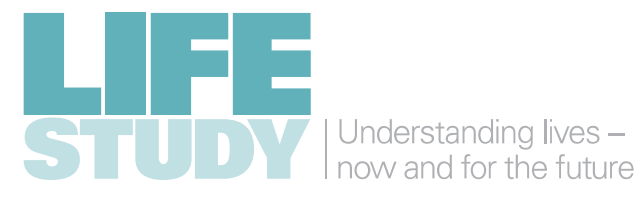

- First Life Study Centre opened in January 2015

- Second Life Study centre opened in September 2015

- Opening of centres delayed by $\sim 6$ months (contract \& build)

- Recruitment in first centre slower than anticipated

- May 2015: only 194 mothers and 64 partners recruited

- June 2015: SSC and ISAC reviewed recruitment, strategies to augment recruitment \& study power given lower projected final sample size 


\section{When was Life Study closed?}

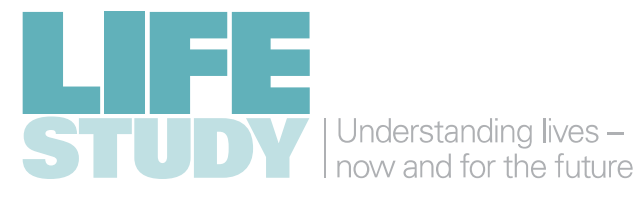

July 2015

- Gateway zero review: amber/red

- Recognised problems with recruitment and concluded "These appear resolvable with prompt and decisive action by all parties."

- ESRC Council decided to close Life Study the day after the Gateway report was shared with UCL

September 2015

- Meeting of Scientific and Operational Audit Panel established by funder to decide how (not if) to close

October 2015

- Panel recommended immediate closure

- Funders issued 3 month termination notice to $\mathrm{UCL}$

- Participants contacted before public notice issued and recruitment to pregnancy component ceased at both sites 


\section{How many participants and what was collected?}

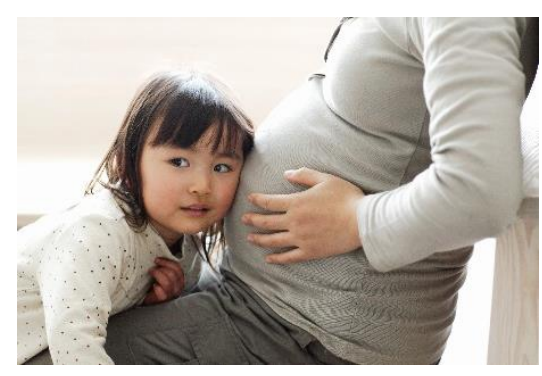

Pregnancy: BHRUT

$>336$ mothers recruited

$>105$ fathers recruited

$>$ Biological samples: 238 mothers and 68 fathers/partners

$>$ High \% consenting to record linkage

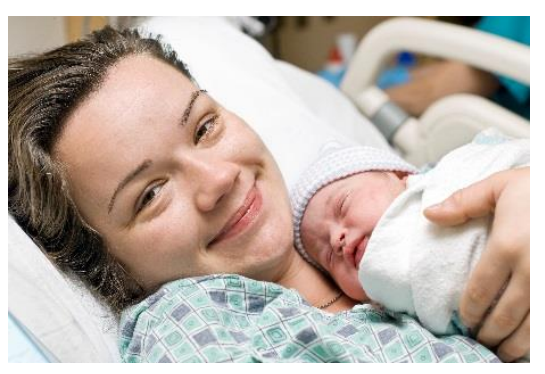

Birth: BHRUT

> 46 Placentas collected before closure of Study (from July 2015)

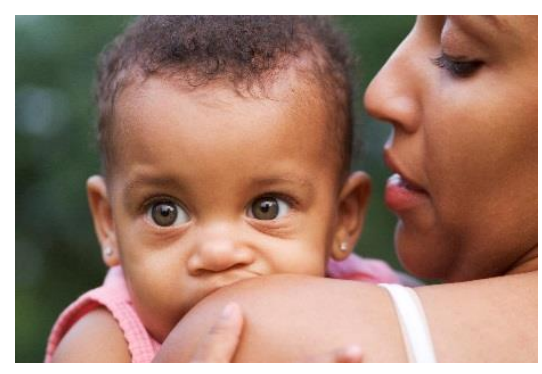

6 months

$X$ None initiated

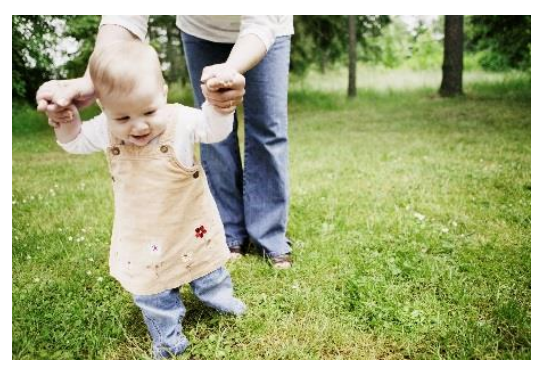

12 months

X None initiated 


\section{Next steps}

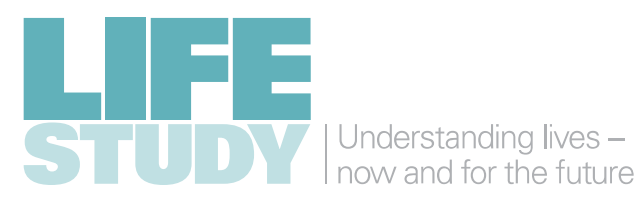

- Life Study Advisory Group on Ethics has met and considered ethical perspective, consent given by participants and disclosive risks

- Pregnancy Component data and samples to be transferred to Peter Brocklehurst as PI of Wellcome Trust funded microbiome study

- Participants will be written to with this information

- A legacy website is being established containing information for participants (including withdrawal page) as well as for researchers

- The website will make Life Study publications, protocols and documentation freely available and downloadable from UCL Discovery

www.lifestudy.ac.uk 


\section{What challenges did we encounter?}

- Midwife shortage - meaning only $50 \%$ of women attending scans were approached by midwife

- Follow up contact with mothers difficult and reduced numbers of booked appointments

- About half the mothers with booked appointments did not attend (some reduction once vouchers started)

- Visit too long overall (questionnaire reduced further)

- Study was closed before we could implement aligned scan and Life Study visit and other changes

- Integration within NHS key for a study recruiting in pregnancy however challenges in IT, IG and HR 


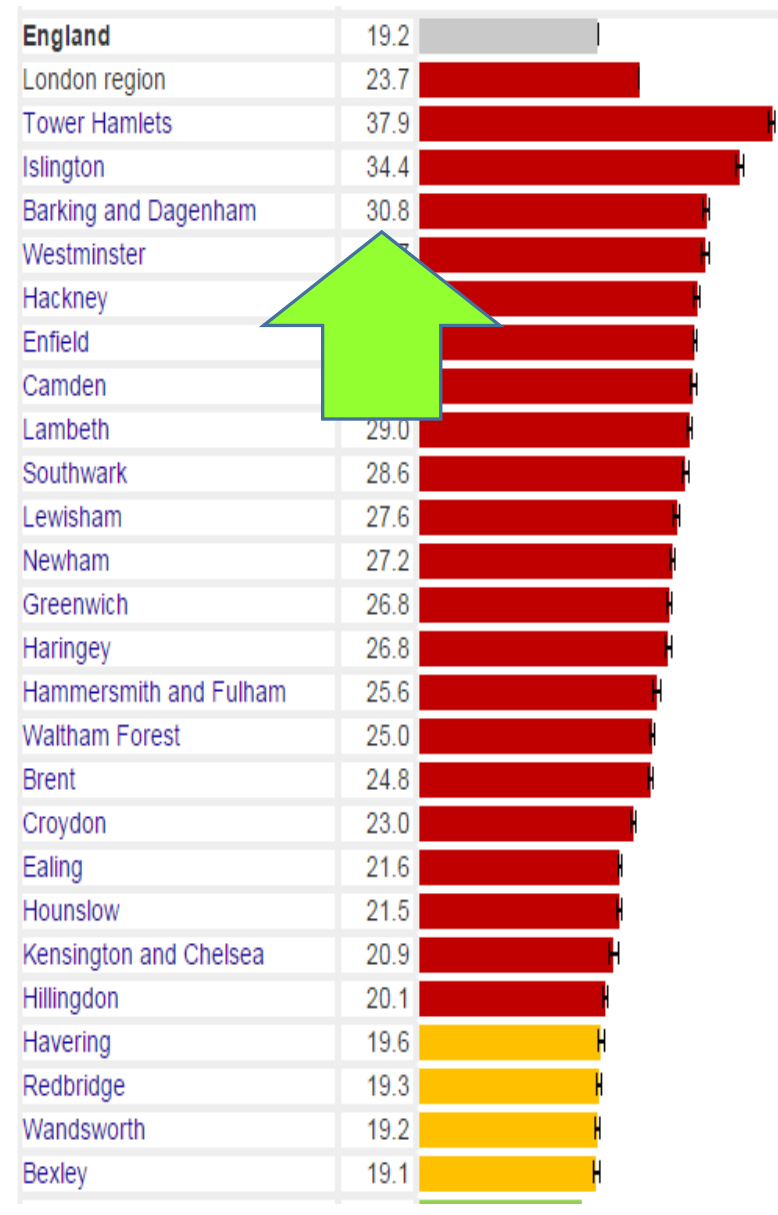

Barking \&

Dagenham

$30.8 \%$

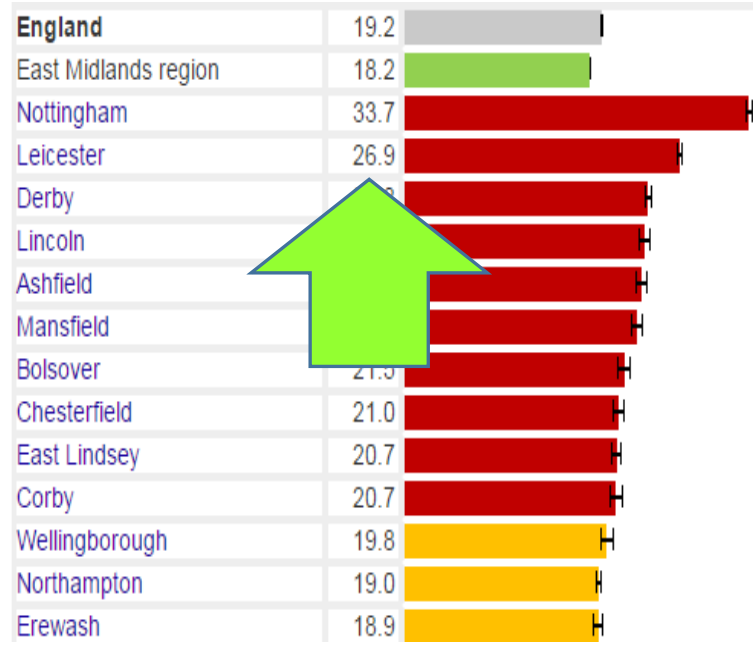

Leicester

$26.9 \%$
Bradford

$23.9 \%$

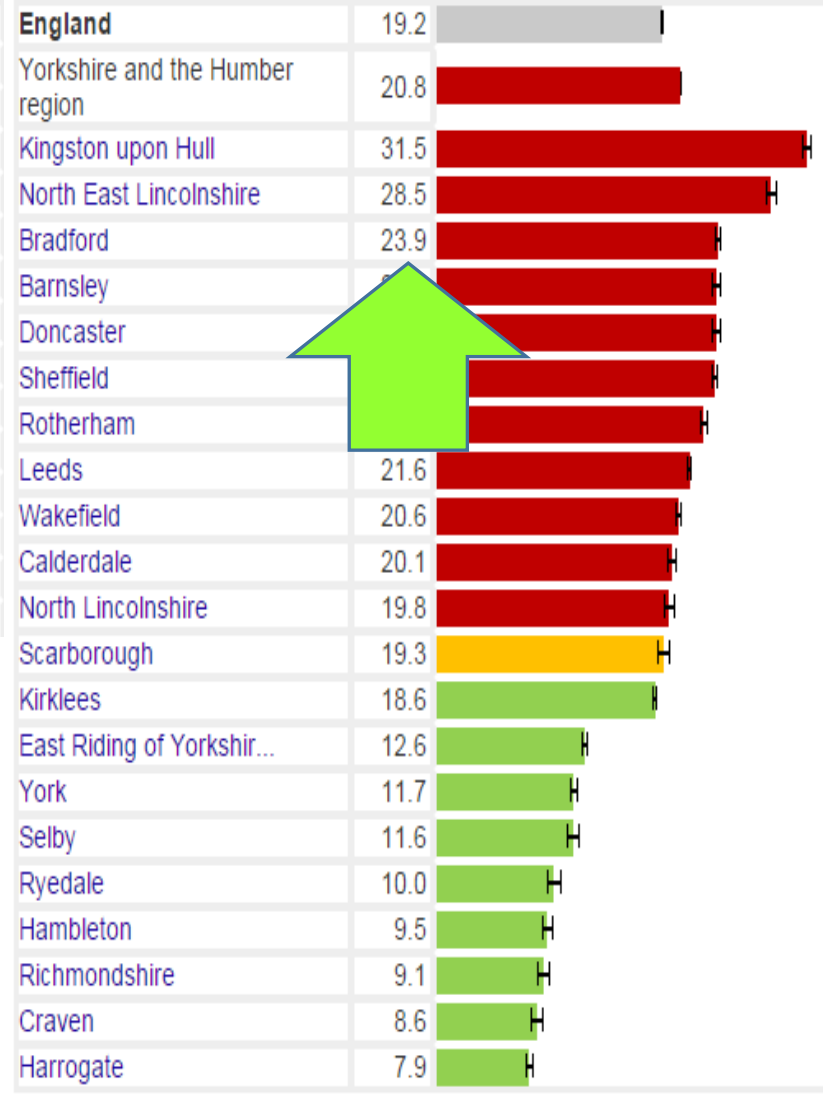

Harrogate

Bradford

Sheffield

Wakefield

North Lincolnshire

East Riding of Yorkshir...

Hambleton

Richmondshire

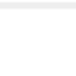

Bradford
$23.9 \%$




\section{Lessons learnt - some initial thoughts}

- Excellent community engagement however hard to reach populations may struggle to attend research clinics

- Patterns of antenatal care make 'golden moment' to integrate antenatal and study visits challenging: could not replicate $\mathrm{BiB}$ integration with (non universal) GTT

- Midwife model of recruitment (as indicated by focus group work) not viable

- Recruitment not fully tested due to cancellation of Study

- Tension between desire for disciplinary breadth (questionnaire length) and participant burden

- Consent to multiple visits at outset increased complexity 
Life after Life Study....

\section{STFE}

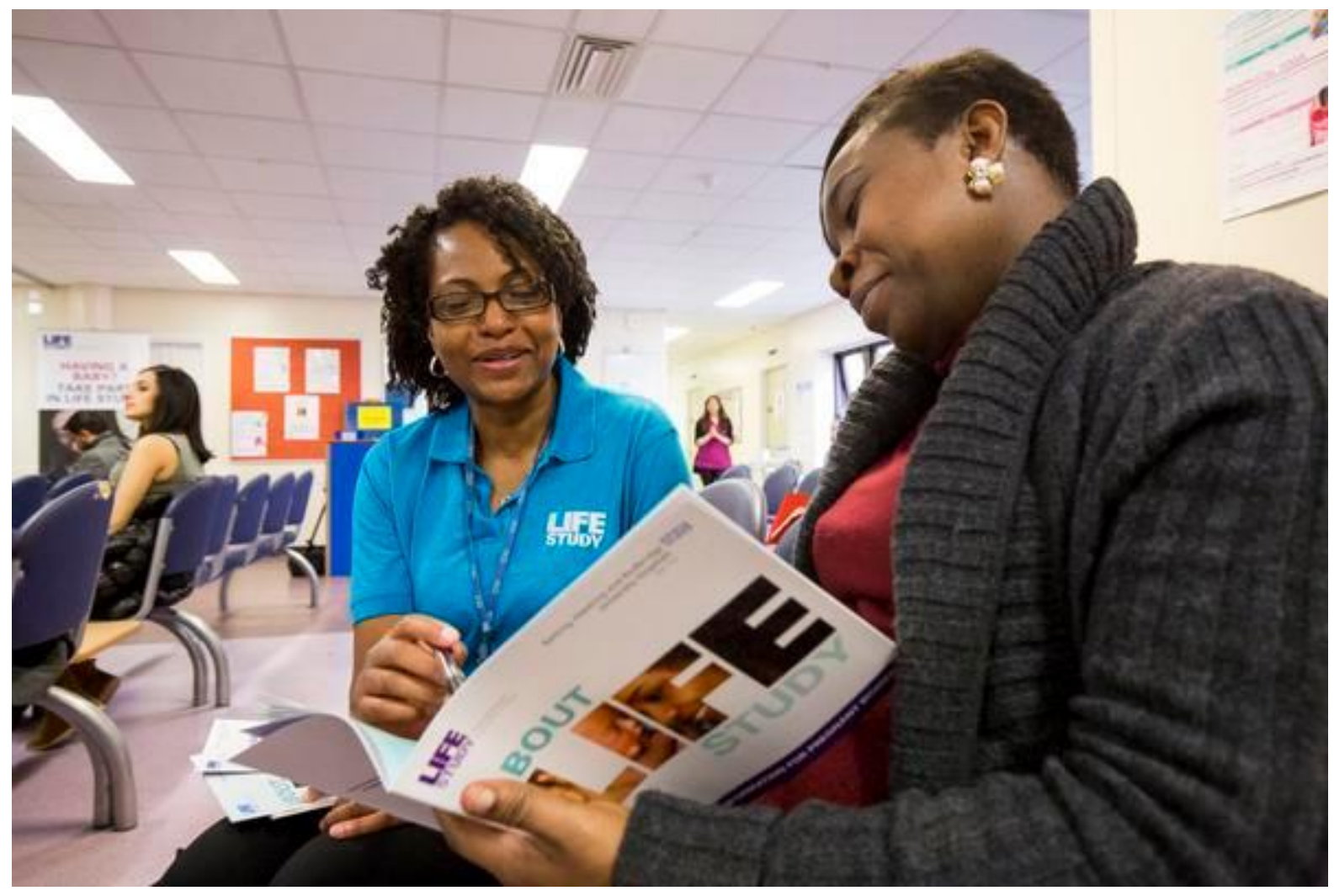




\section{Life Study - challenges and opportunities: piloting the Birth Component}

Life Study Scientific Meeting,

London, 14 ${ }^{\text {th }}$ January 2016 


\section{Background}

\section{Tenders for the Birth Component fieldwork}

- Invitation to Tender posted August 2014

- Ipsos MORI selected as preferred bidder November 2014

- Recommendation from Ipsos MORI to conduct a pilot survey prior to the main survey.

\section{Design of the pilot}

- Sample frame to be provided by three statistical authorities of UK from linked birth registration/NHS records.

- Agreement for pilot sample from ONS and NRS (England and Wales, Scotland).

\section{This presentation}

- How was the pilot sample designed?

- How was it conducted and what was the result?

- What work remains to be done?

- What have we learnt? 


\section{Pilot sample design}

- 'Purposive' sample designed to test: ability of statistical authorities to sample from linked NHS/birth registration records to the required specification (eligibility, date of birth, gestational age); contact procedures; questionnaire scripts; consent procedures; data transfer; data linkage.

- Experiment built into the design to test variation in contact procedures on willingness to participate by mothers.

- Following detailed analysis of 2013 births by postcode sector, 32 postcode sectors selected - good spread across England, Wales and Scotland, predominantly urban areas.

- Detailed report on sample design and contact procedures produced by Ipsos MORI. 


\section{How was the pilot conducted and what was the result?}

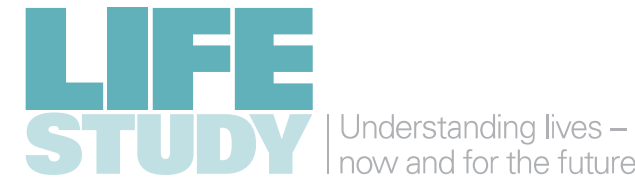

- Fieldwork conducted over a three month period in Autumn 2015. Net response rate (opting-in and providing useable contact details) was lower than expected $-15.5 \%$.

- 'Experiment' (8 page v. 2 page recruitment questionnaire) showed significant difference in agreement to participate (18.7\% v. $12.0 \%)$.

- Sampling by expected as opposed to actual date of birth successfully conducted by ONS.

- Development of questionnaires in SQL database by UCL significantly improved speed and efficiency of scripting.

- Interviewer briefing and interviews with mothers and fathers went smoothly - recommendations to trim interviews, restructure consent procedures.

- Separate report on fieldwork prepared by Ipsos MORI. 


\section{What work remains to be done?}

- For England and Wales - data from full sample (interviewed plus not interviewed) now available in the ONS VML to Life Study team members with approved researcher status.

- Analysis of these data as follows:

- Comparison of characteristics of England and Wales sample $(4,078$ live births) with all live births (age of mother, ethnicity, country of birth, social class, term of birth, area).

O Within sample of 4,078 live births, analysis of response rate by above variables plus 'experimental group'.

- Dataset and documentation now being prepared for deposit with UK Data Service. 


\section{Lessons learnt - what could have been done?}

- An opt-in approach using birth registration records to the establish the first wave of a birth cohort study is not a viable proposition.

- Birth registration records, linked to NHS records, yield an accurate, up-to-date and comprehensive sampling frame for a longitudinal study. Linkage to such records provides the basis for innovative study designs which combine recruitment via clinics with traditional household sampling techniques.

- An opt out approach to the design of a national probability sample for a birth cohort is required. This is a feasible proposition and was being actively pursued by the Life Study team and Ipsos MORI when Life Study was cancelled. 


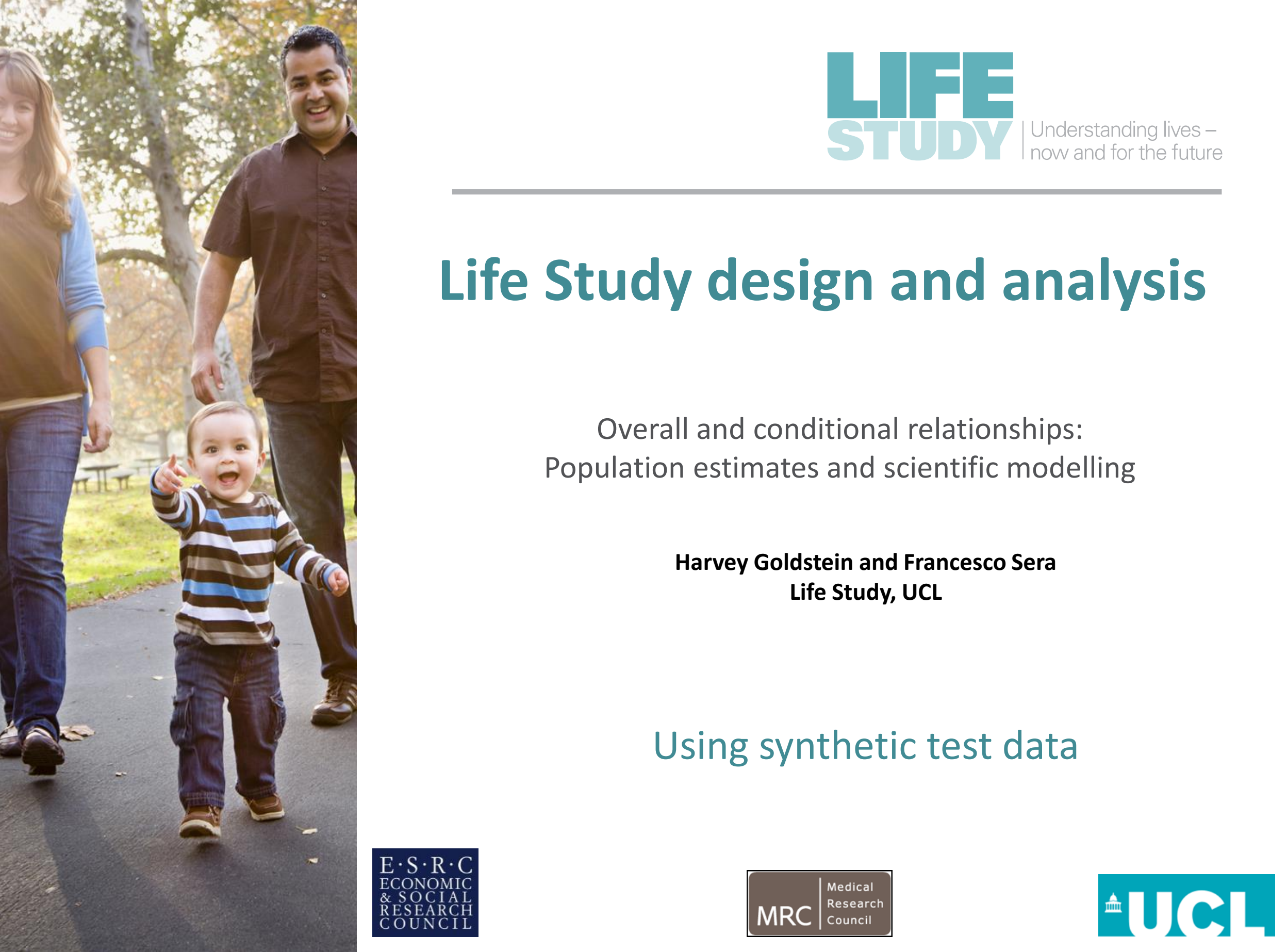




\section{Integrating pregnancy and birth components}

- Users require a single combined dataset

- The components not only have different measures, they 'represent' different groups of babies

- How do we combine for the purposes of:

- Making 'population' inferences (as previous cohorts)

- Fitting explanatory models for exploring causality

- We illustrate the issues and how we had planned to tackle them using a synthetically generated dataset. 


\section{Data generated to mimic ONS births 2013}

Variables used (Strata):

SES (4), Maternal age(4), bwt(4), ethnicity(4), sex(2).

\section{This forms a 5-way table}

- Two components: Births (16k) with a structure as 2013 population

- Pregnancy (60k) with a structure over-weighting minority groups

- Modelling relationship between an outcome and an exposure; target values:

- Within cells of table: $y=0.50+0.20 x$

- Marginal relationship: $y=0.15+0.65 x$ (2)

TABLE 1. Ignoring strata: marginal population estimates (actual=0.62)

\begin{tabular}{|l|l|l|}
\hline & Coefficient & S.E. \\
\hline Birth component (weights) & $0.62(0.62)$ & $0.006(0.0058)$ \\
\hline Pregnancy component (weights) & $0.51(0.65)$ & $0.003(0.028)$ \\
\hline Combined (weights) & $0.54(0.62)$ & $0.003(0.0056)$ \\
\hline
\end{tabular}

- Inferences:

- Differential weighting increases S.E. Especially for pregnancy - but not for births where weights designed to be equal.

- Adding pregnancy component to births for weighted decreases S.E. only minimally for weighted, but halves it for unweighted.

- No increase in efficiency from adding pregnancy component to obtain population estimates using the weights, reflects the fact that overall pregnancy component is only $4 \%$ of population with relatively more minority groups. Average weight is in ratio about 60:1 to reflect this. 


\section{Scientific modelling}

- Table 1 simply provides population estimates.

- Scientifically we wish to model 'true' relationship - in this case model (1)

- So model is now: $y=\alpha+0.20 x+\beta *$ strata variables

- Note that stratum variable coefficients are omitted for simplicity.

TABLE 2. Including main effects model for strata

\begin{tabular}{|l|l|l|}
\hline & Coefficient & S.E. \\
\hline Birth component (weights) & $0.206(0.206)$ & $0.00525(0.00525)$ \\
\hline Pregnancy component (weights) & $0.199(0.192)$ & $0.00267(0.01437)$ \\
\hline Combined (weights) & $0.201(0.205)$ & $0.00238(0.00504)$ \\
\hline
\end{tabular}

- For births - no effect of weights since unweighted.

- For pregnancy note increased standard error when weights are used to estimate for 'population' - while actual estimate little changed.

- For combined sample estimate little changed but increased S.E. for weighted population estimate

- Note greatly improved efficiency (without weights) of using combined over just births (five-fold) and just $26 \%$ by adding births over just using pregnancy component alone. 


\section{Conclusions}

- By conditioning in a model on the relevant stratification variables that differentiate pregnancy from birth component we can estimate the scientific model of interest. We can also adjust for any additional mean differences between components in our models.

- Modelling components jointly is most efficient, but not very much more (about 25\% increase in efficiency) compared to just using pregnancy component.

- Weighting adds nothing to the scientific model estimate and is strictly redundant if we are prepared to accept the validity of conditioning (auxiliary) variables - which are anyway those used to calculate the weights.

- If we simply wish to make overall population estimates of means etc., then the large size of the pregnancy component is offset by the fact that it has an overall relative weight of about $1.7 \%$, so only an overall increase of $2.5 \%$ is obtained.

- For scientific comparisons with previous cohorts that are model based, we will also have the greatly enhanced efficiency (fivefold) from including the pregnancy component.

- Results are not greatly affected by moderate changes in relative sizes of components. 


\section{The Life Study Environmental Enhancement Pilot}

Frank Kelly, Artemis Doutsi, Evridiki Patelarou and Benjamin Barratt 
Objective - to follow the lives of children and their families in respect of the following five main scientific themes

- The impact of inequalities, diversity and social mobility on children's life chances

- Early life origins of specific childhood illnesses and health related behaviours

- Social, emotional \& behavioural development and interactions with parents / care givers

- Early life antecedents of school readiness and school performance

- Neighbourhoods and environmental pollutants 


\section{Aim}

To determine if novel environmental and personalized sampling techniques can be used to better characterise a pregnant woman's environment within acceptable levels of convenience to the participant 


\section{Health Effects of Air Pollution}

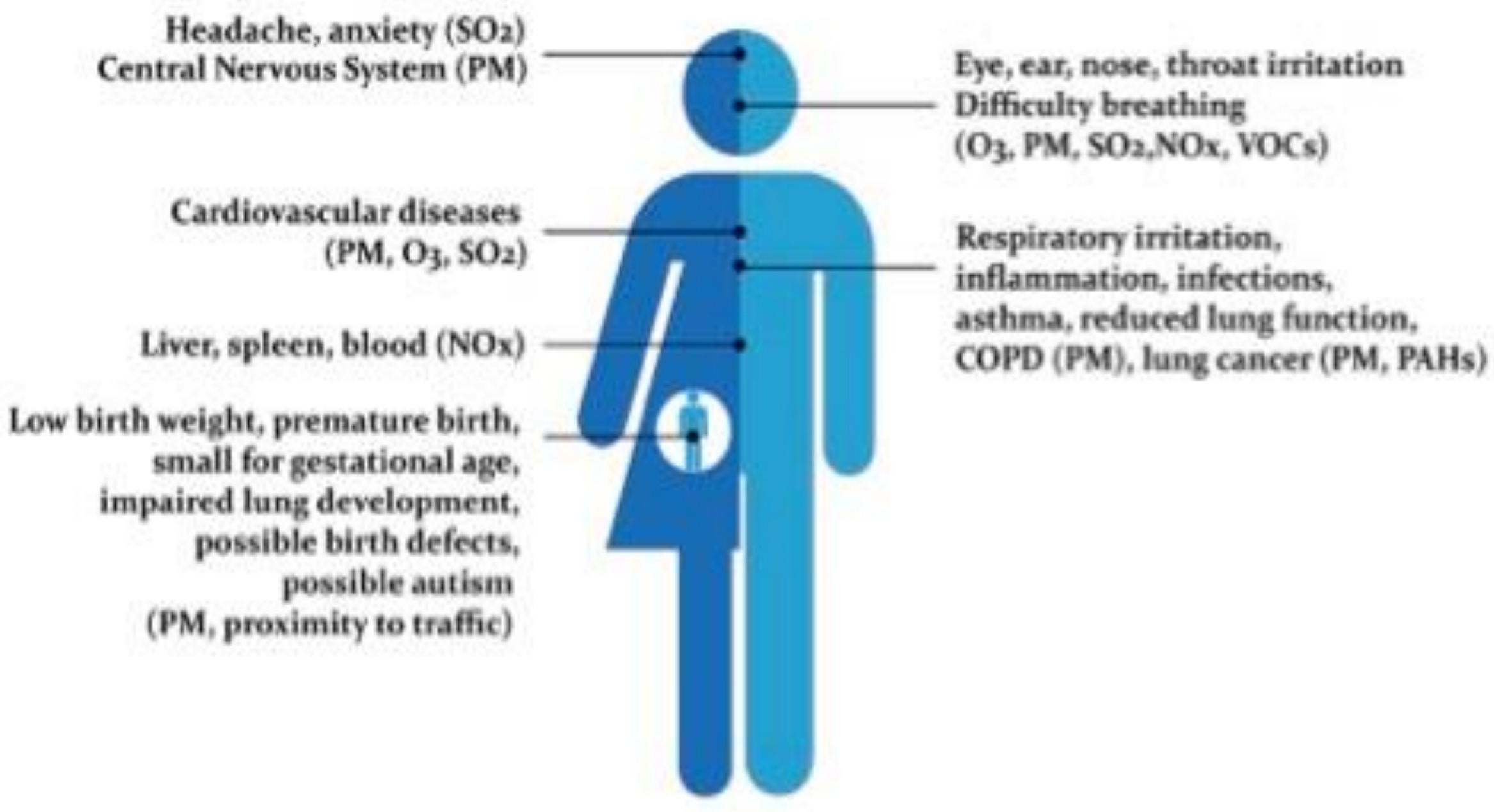



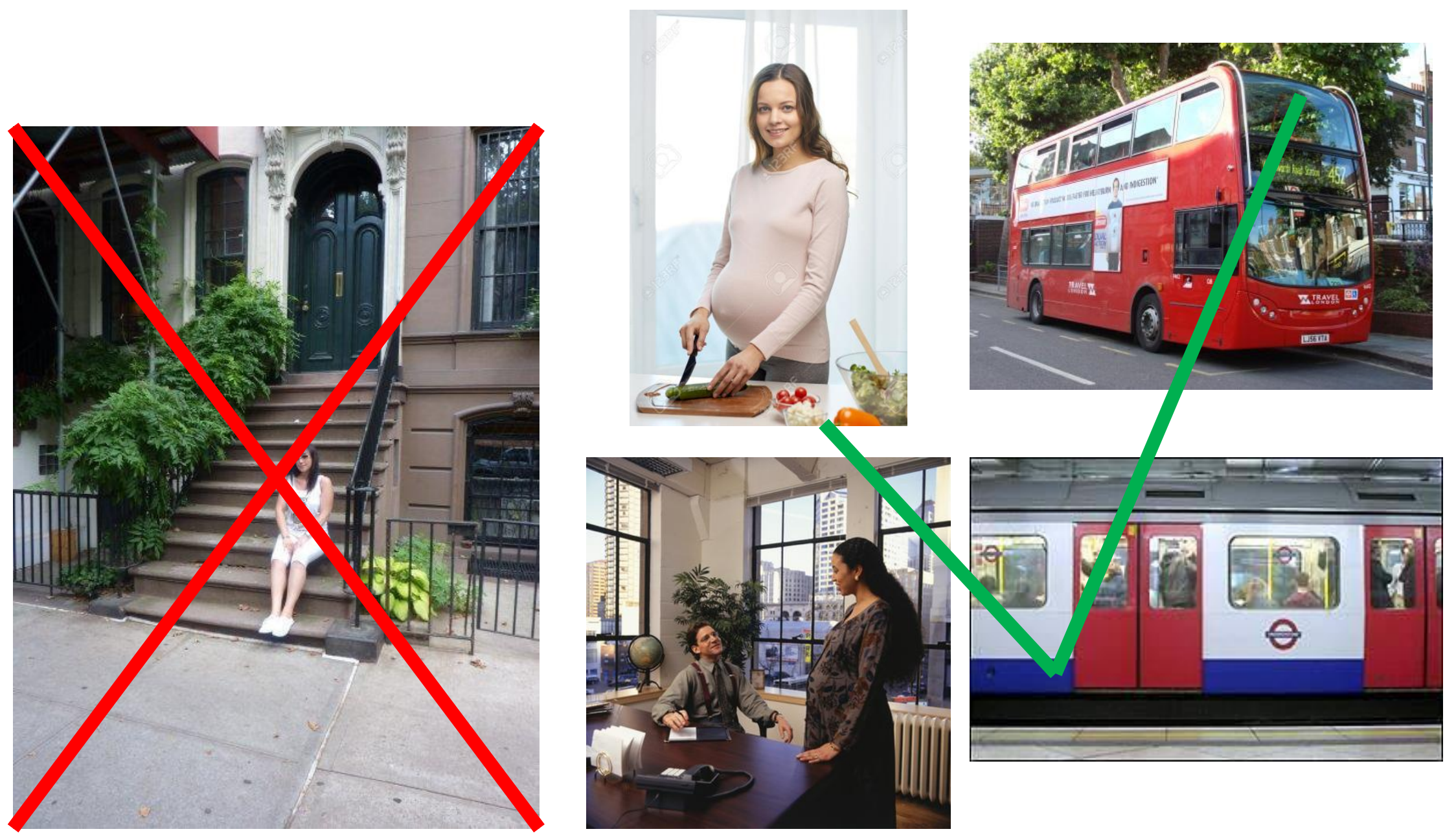

MRC-PHE

Centre for Environment \& Health

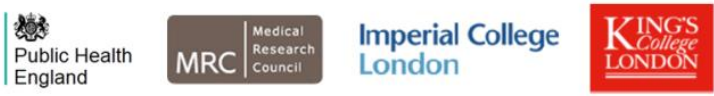



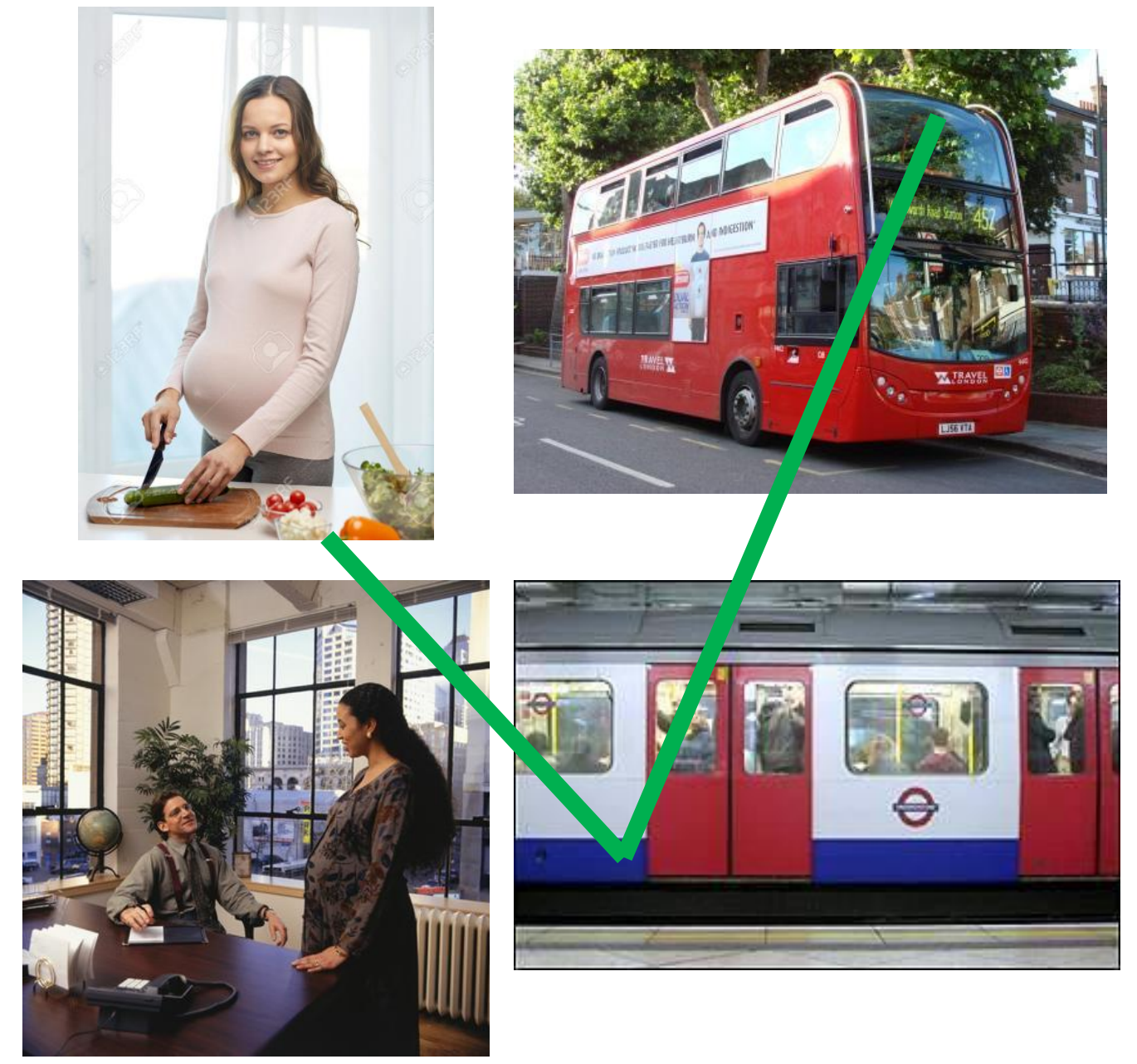

MRC-PHE

Centre for Environment \& Health

\begin{tabular}{|c|c|c|}
\hline ublic Health & MRC & \begin{tabular}{|} 
Mecical \\
Resesarch \\
councili
\end{tabular} \\
\hline
\end{tabular}




\section{Objectives}

- Measure a range of stressors simultaneously: temperature, humidity, air pollutants, noise, EMF, damp, and dust

- Test smart-phone apps and commercial GPS and fitness devices on positioning and physical activity

- Develop personalised exposure models

- Record participant response, experiences, feedback and completion rates

- Identify areas of improvement for safe up-scaling to a potential full scale birth cohort study 


\section{Study Design}

- Study group: 21 pregnant women (representative sample)

- Inclusion criteria:

- Singleton pregnancy women, 3rd trimester, aged 18-45

- Residence in Greater London

- Informed consent

- Sampling period: 7 consecutive days

- Fieldwork duration: March - July 2015

- No biological samples were taken and only non-invasive metrics used

- Some metrics were duplicated to test different methods/technologies 


\section{Study Design}

- Recruitment centre: St Thomas' Antenatal Ultrasound Department

- Home visit duration: 45-60 minutes

- First home visit

- Environmental monitoring units installed

- Personal devices/mobile phone apps delivered to participants

- Minimal training

- Second home visit

- Collection of monitoring units

- Dust sampling, multi-room spot-check measurements

- Face-to-face interview to log participant experience and subset of Life Study questionnaire 
LIFE STUDY SUBSET

plus participant feedback

IGOTU GPS tracker

FITBIT FLEX Activity

Smartphone Apps Sleep, activity, GPS
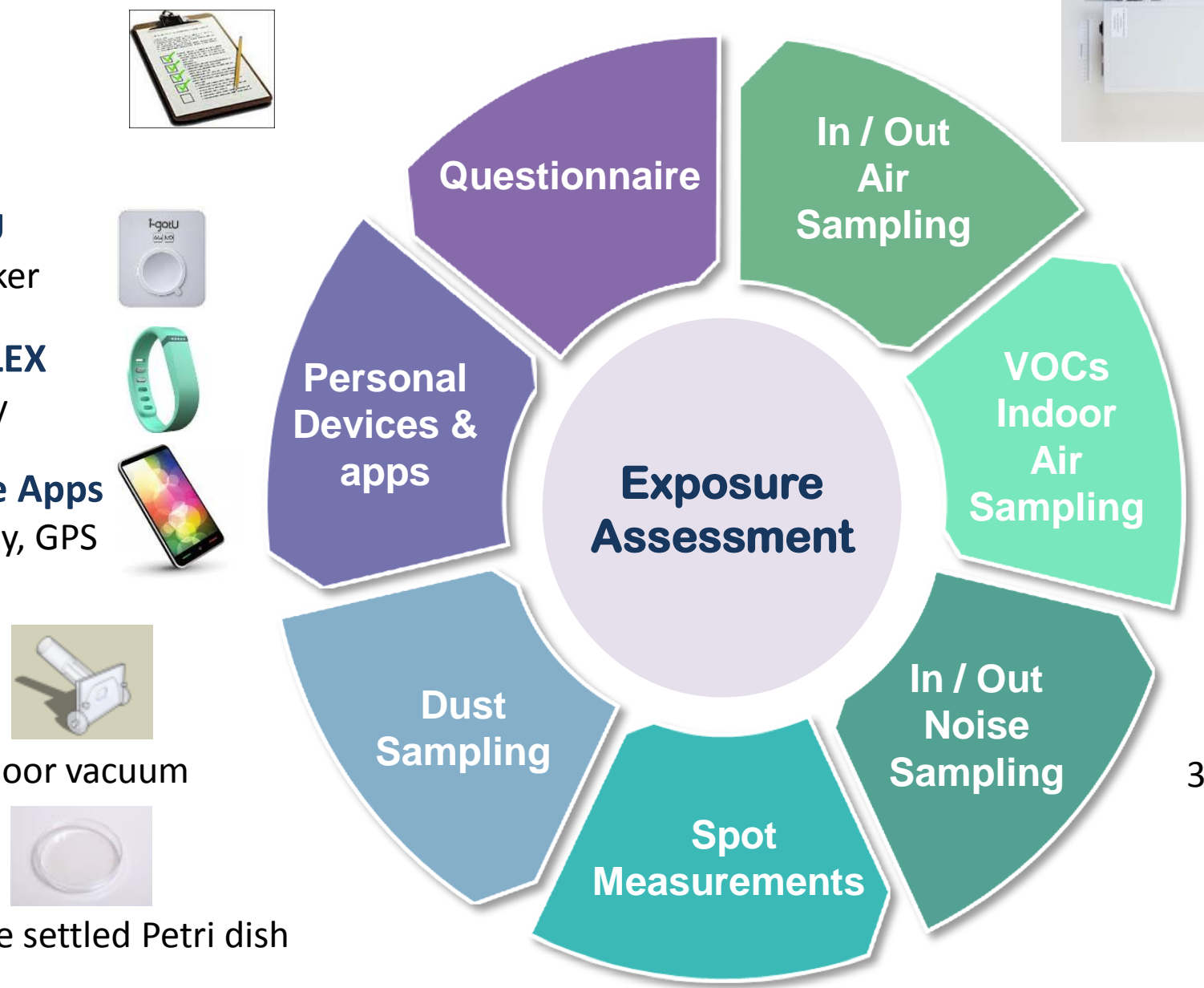

Floor vacuum

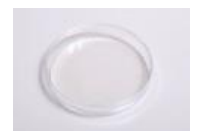

Airborne settled Petri dish

CEM 125B

Surface Moisture

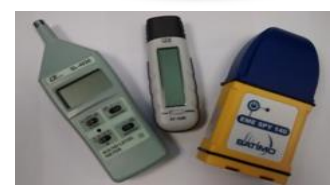

EME Spy 200

EMF frequency
SNAQ WIRELESS SENSOR UNIT

- $\mathrm{CO}, \mathrm{NO}, \mathrm{O}_{3}, \mathrm{SO}_{2}, \mathrm{NO}_{2}$

-PM 0.38 to $17.4 \mu \mathrm{m}$

- $\mathrm{CO}_{2}$ \& TVOCs

- Temperature and $\mathrm{RH}$

SUMMA CANISTER 6lt Offline GC analysis of VOCs

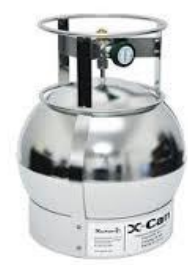

\section{EXTECH}

30-130 dB noise logger

\section{SL4030}

Noise meter 


\section{Recruitment Results}

- 85 pregnant women that were eligible for participation were approached

- 21 accepted and took part in the study (24.7\% response rate)

- Accommodation of the static home monitoring unit was the most common cause of refusal

- Awareness of issues from media coverage increased willingness to take part

- $0 \%$ drop out - Likely to be due to the autonomous and noninvasive methods used 


\section{Participant feedback}

- Overwhelmingly positive questionnaire feedback

- No inconvenience and privacy issues were recorded

\section{Ease of technology use}

"The sleep app was interesting. And...umm as I mentioned the activity. Seeing how active I was...”

"Going out with the mobile...that was the part that was funny...not funny but I don't know how to explain..."

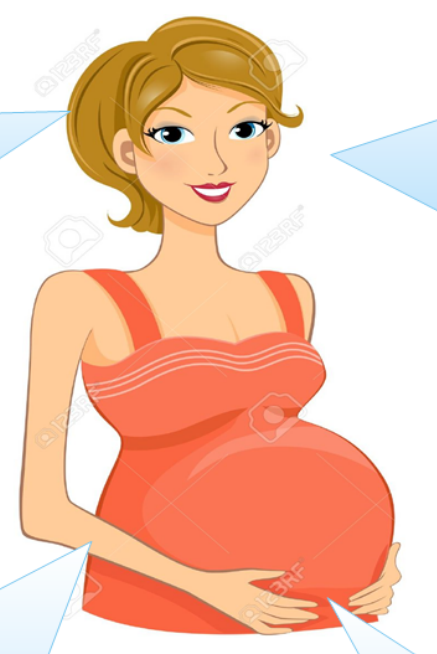

\section{Value of participation}

"I was interested in helping. To help other people."

"The fact that it was looking at something that hasn't been looked at properly before.."

"I was part of something. I was helping someone as well. Helping the environment, helping someone."

\section{Suggestions for improvement}

"I know I'm being cheeky but it would be a good incentive if you could give something as a gift."

"Hmm....it would be better to do this online...."

"It would be much better to incorporate into one equipment. That would make it user friendly and efficient.."

"Just providing some advice and education on how we can prevent risk would be very important."

\section{Need for feedback- advice}

"I would be interested to know what information comes back saying about pollution, noise, what my pattern actually tells and how I can change it."

"It would be interesting to know the results, for pollution...so it would be great to know so that I can help myself and my baby." 


\section{Concluding Remarks}

- Results tie together information from a wide range of environmental stressors to which the pregnant women are exposed

- The integration of novel methods and tools produce useful results in assessing exposure objectively, effectively and qualitatively

- Multi-stressor environmental and personal data are combined with lifestyle factors, enabling a more quantitative investigation on how complex sets of life style factors can influence exposure patterns

- Participant acceptability results indicate that the utilisation of adopted methods and tools is suitable and can be extended to data collection for larger groups and other cohorts 


\section{Concluding Remarks}

- Spatio-temporal GPS data can be applied to assess behavioral activity and exposure characterization when coupled with appropriate modelling tools.

- Researcher use of smartphone apps and 'personal tech' appears to be more acceptable than home-based monitoring, despite more personalised information.

- Smartphone and personal tech is relatively scalable.

- Consider how information from such studies should be fed back to the participants and the public without undue worry 


\section{Personal monitoring has evolved during the short course of the LIFE Study}

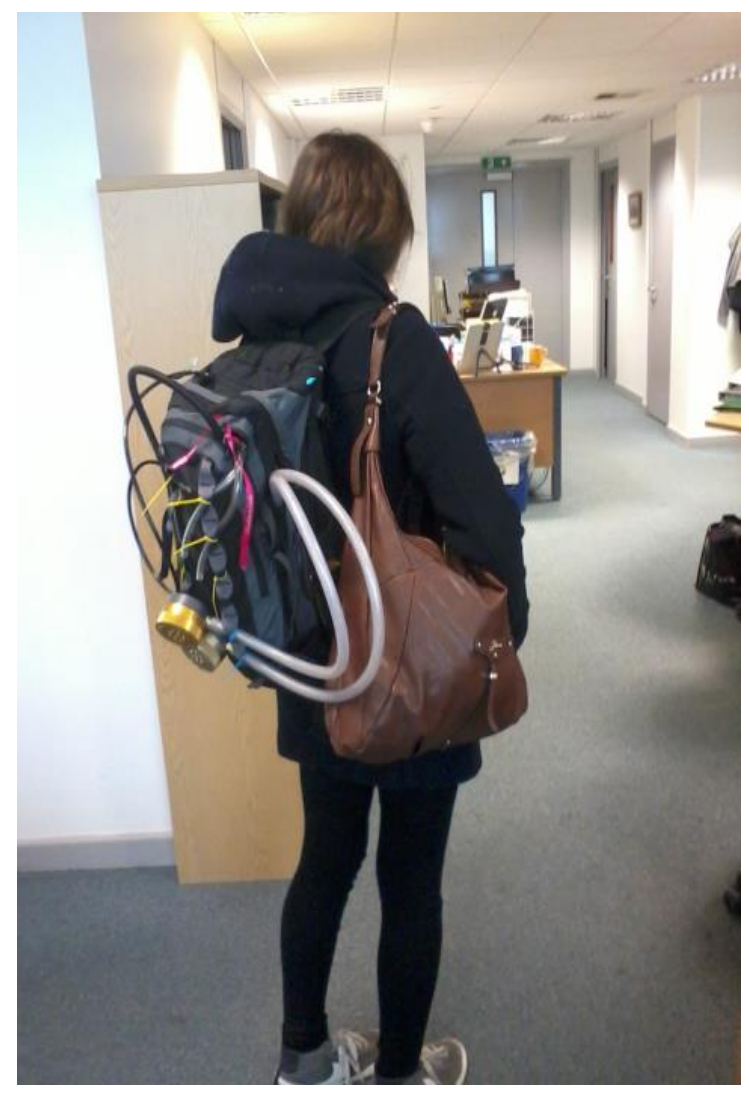

2012: Multi-parameter, but bulky

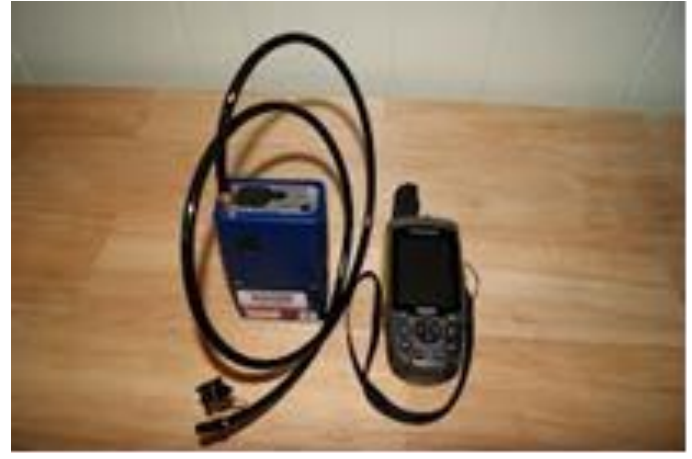

2013: Small, single parameter

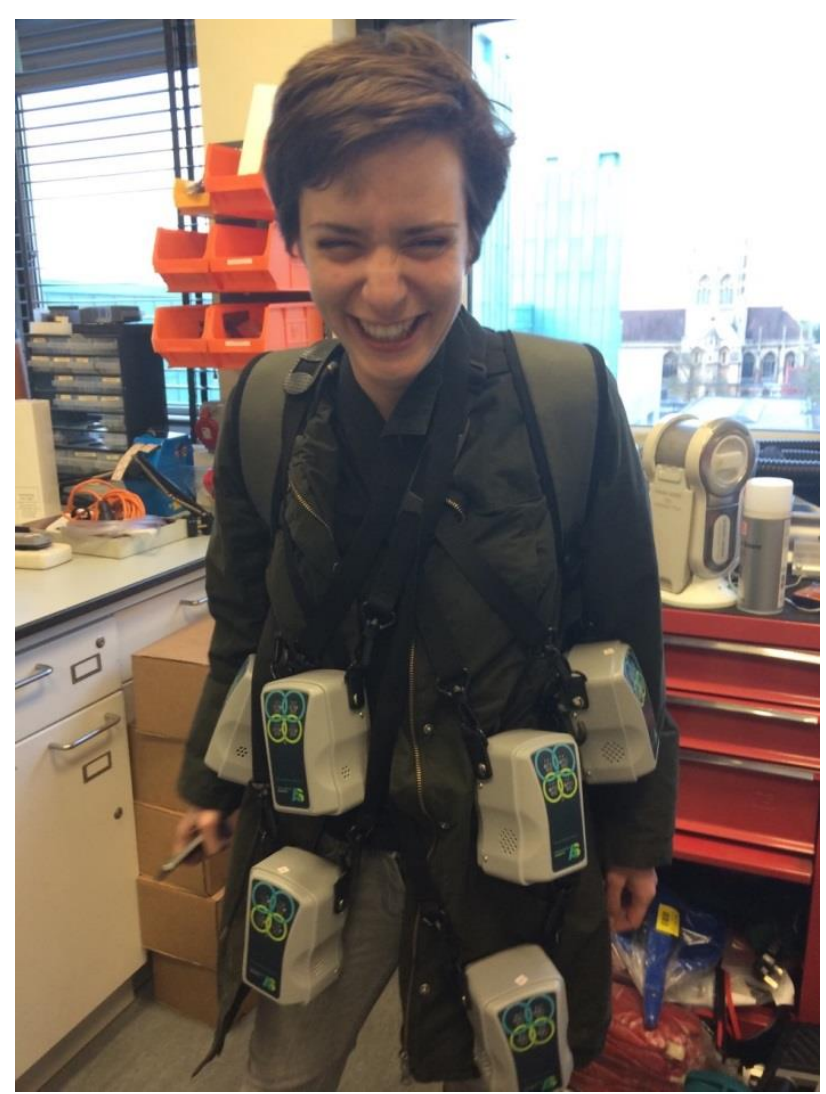

2015: Multi-parameter and small (six carried at once for testing!) 


\section{Placental Assessment:}

\section{Methodological aspects}

Neil Sebire

$\mathrm{GOSH} / \mathrm{ICH}(\mathrm{UCL})$

London UK

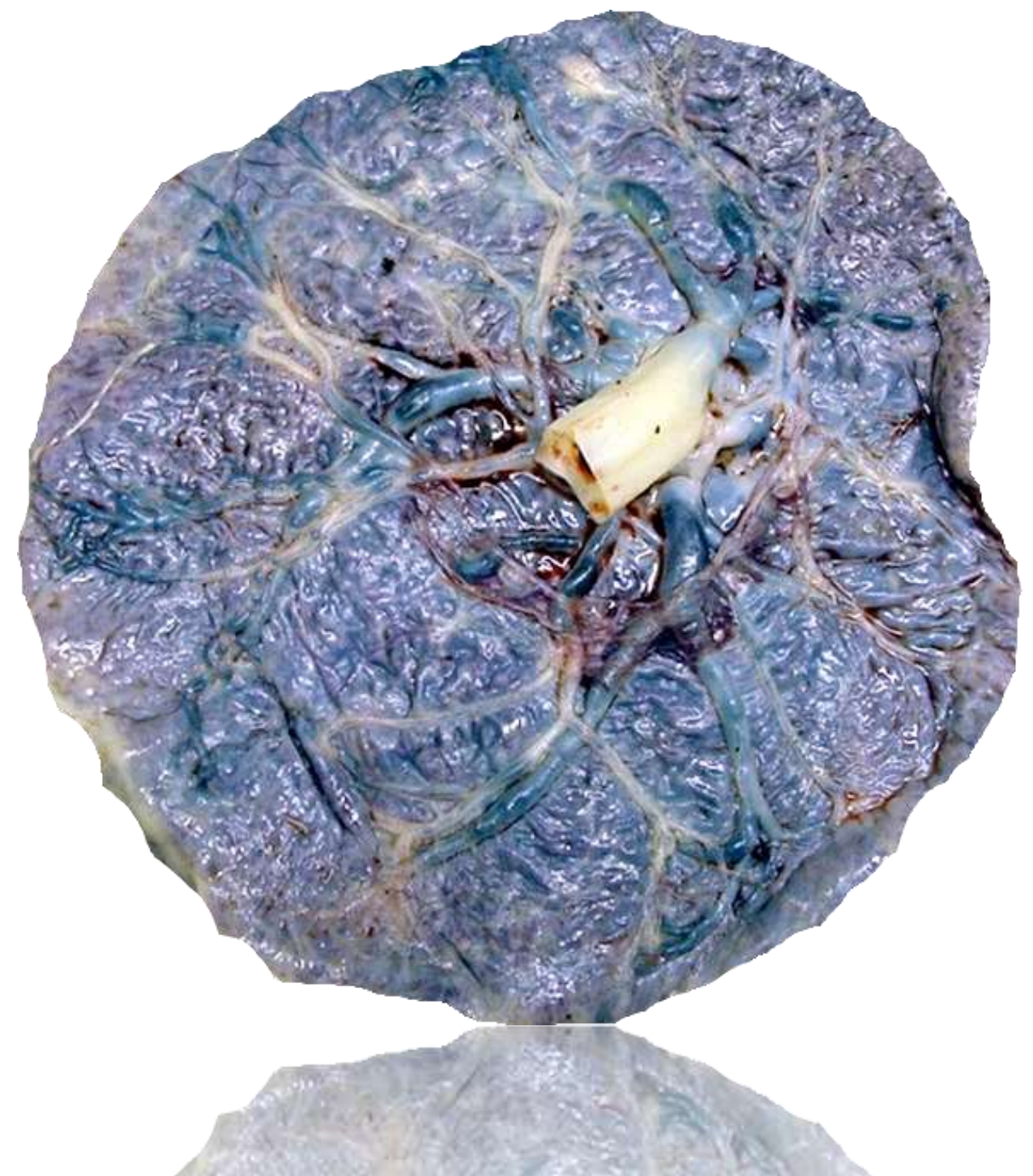


Morphometry

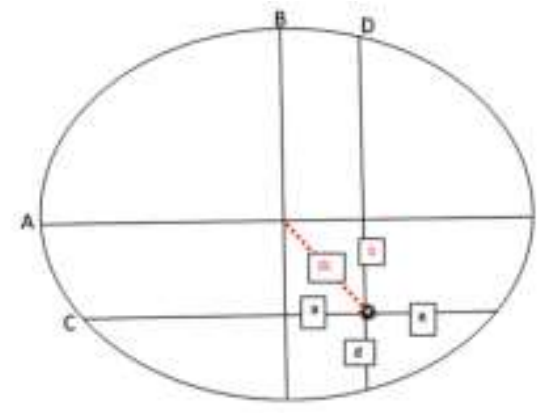

Histomorphology

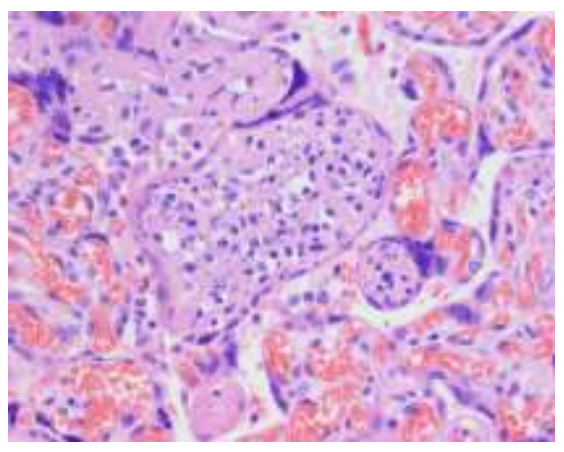

Histomorphometry /

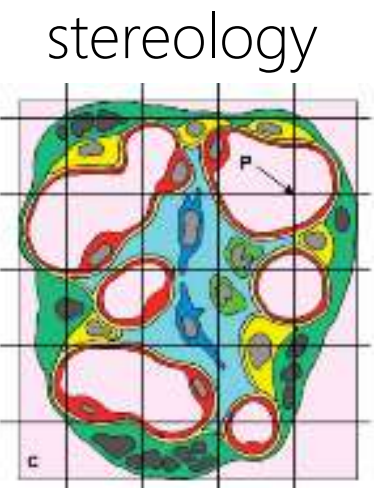

Techniques in Placental Pathology

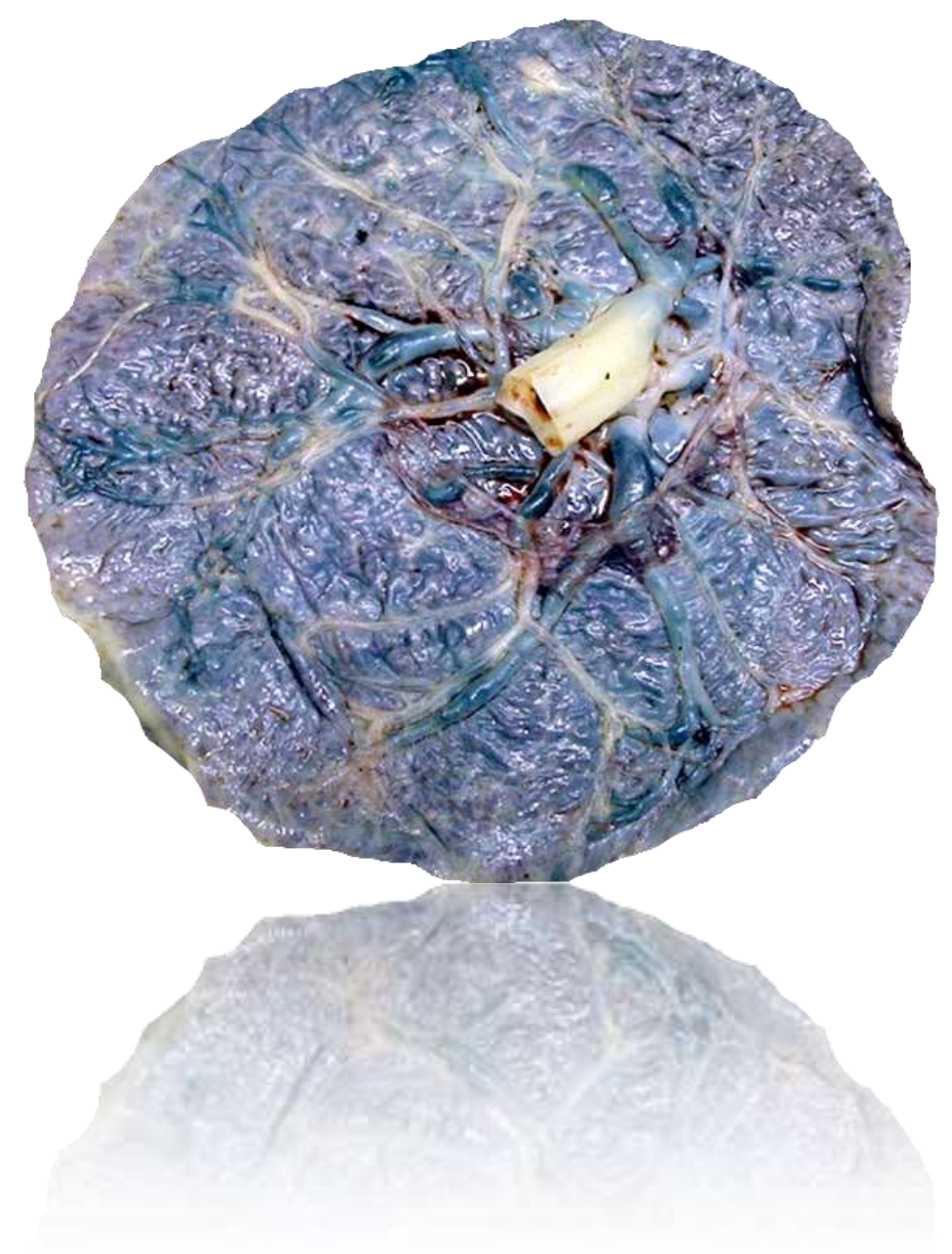

Injection studies

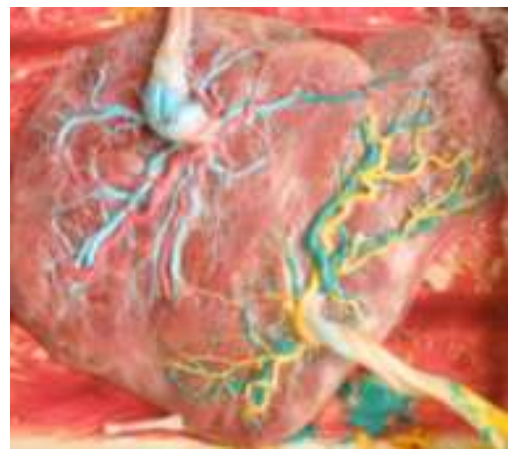

Expression / OMICS

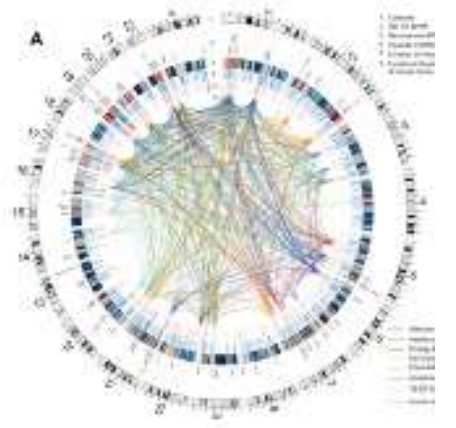

Immunostaining

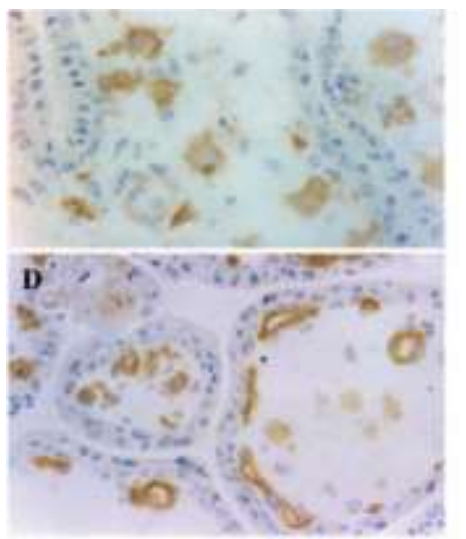




\section{Aetiology of spontaneous PTB:}

\section{Studies of pathology}

30-50\% infection / inflamm

20-30\% uteroplacental disease / ischaemic?

20-30\% No pathological entity

Salafia et al 1992, Arias et al 1993
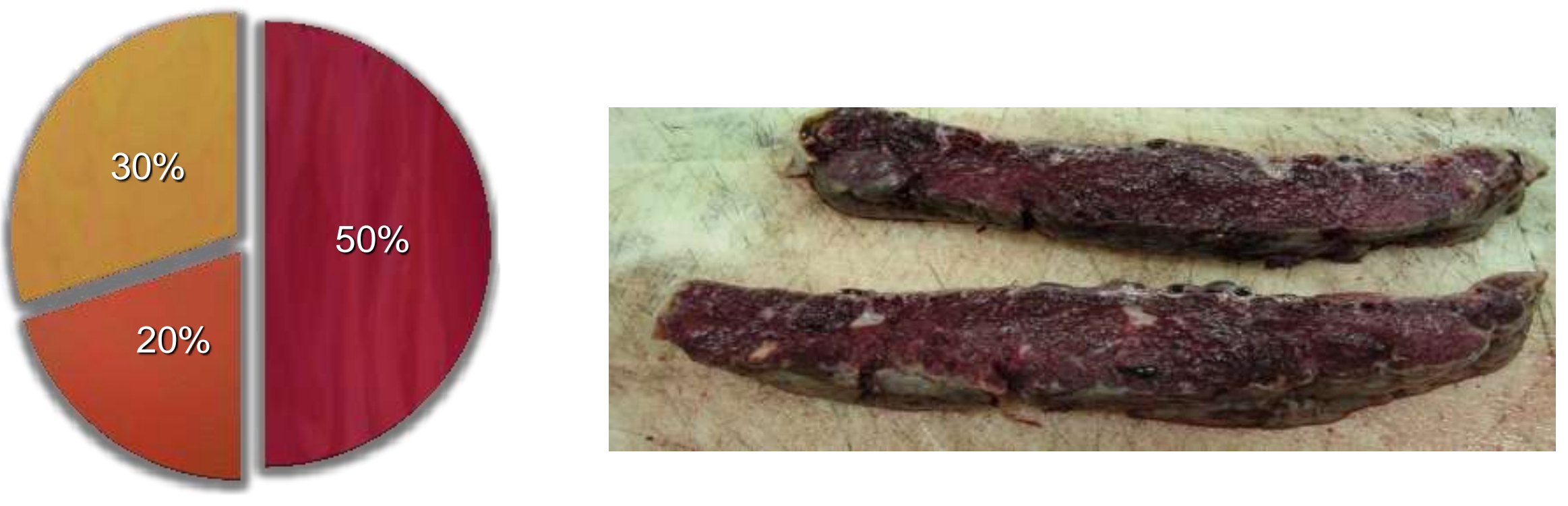

Infection $\quad$ UPD $\quad$ Nil 


\section{Chorioamnionitis and brain injury}

Histologic CA in term infants

relation to $C P$

RR 8.9 (95\% CI 1.9-40)

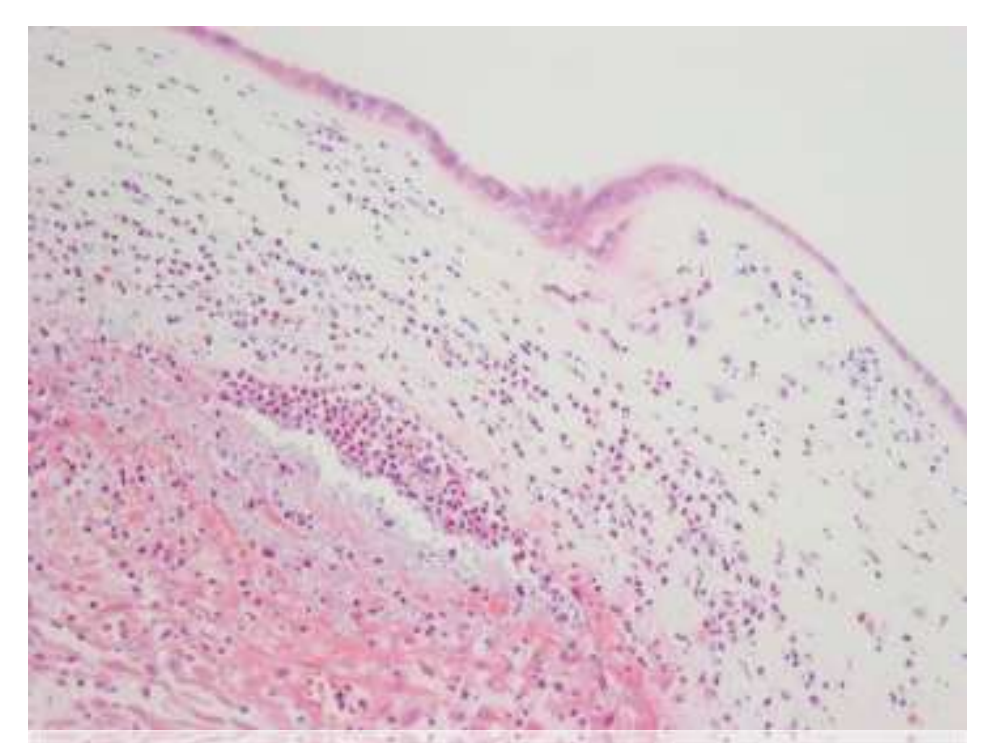

?direct effect or via chorionic plate thrombi 


\section{Placental changes in IUGR}

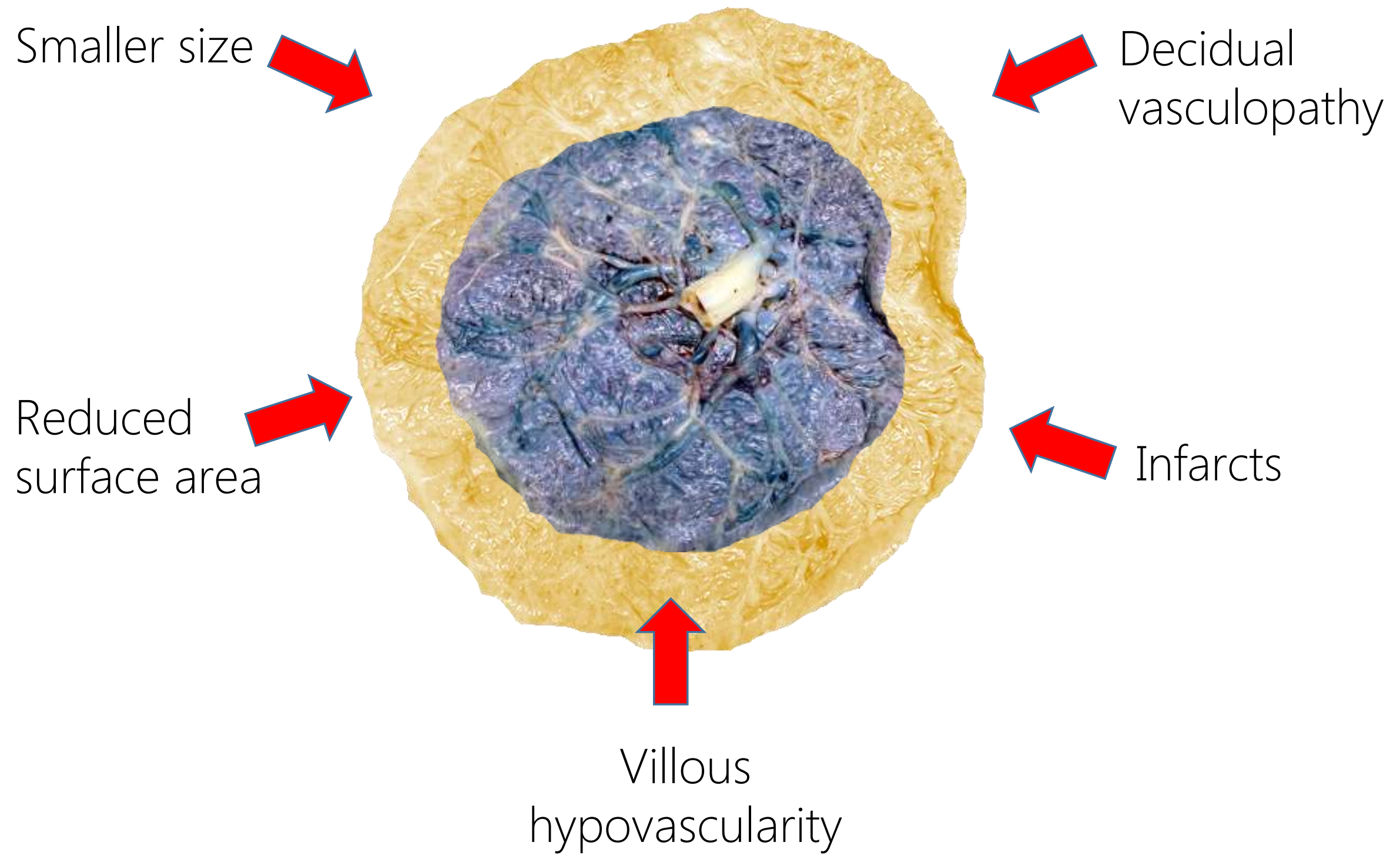




\section{Placental changes in IUGR}

Reduced villous

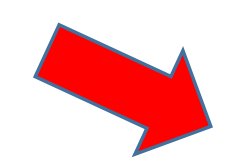

branching

Increased

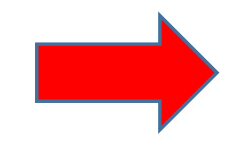
Maturation /

Terminal

villous

hypoplasia
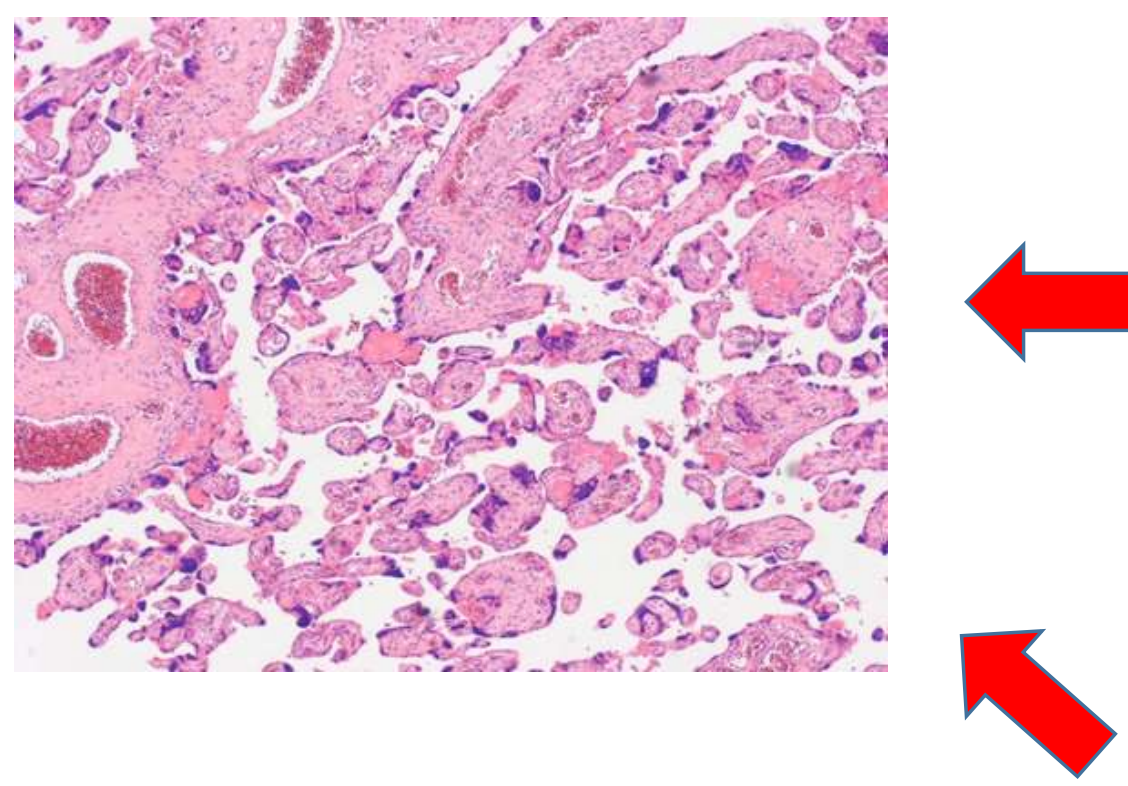

NRBCS

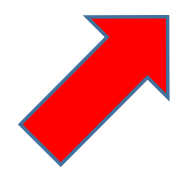

Villitis
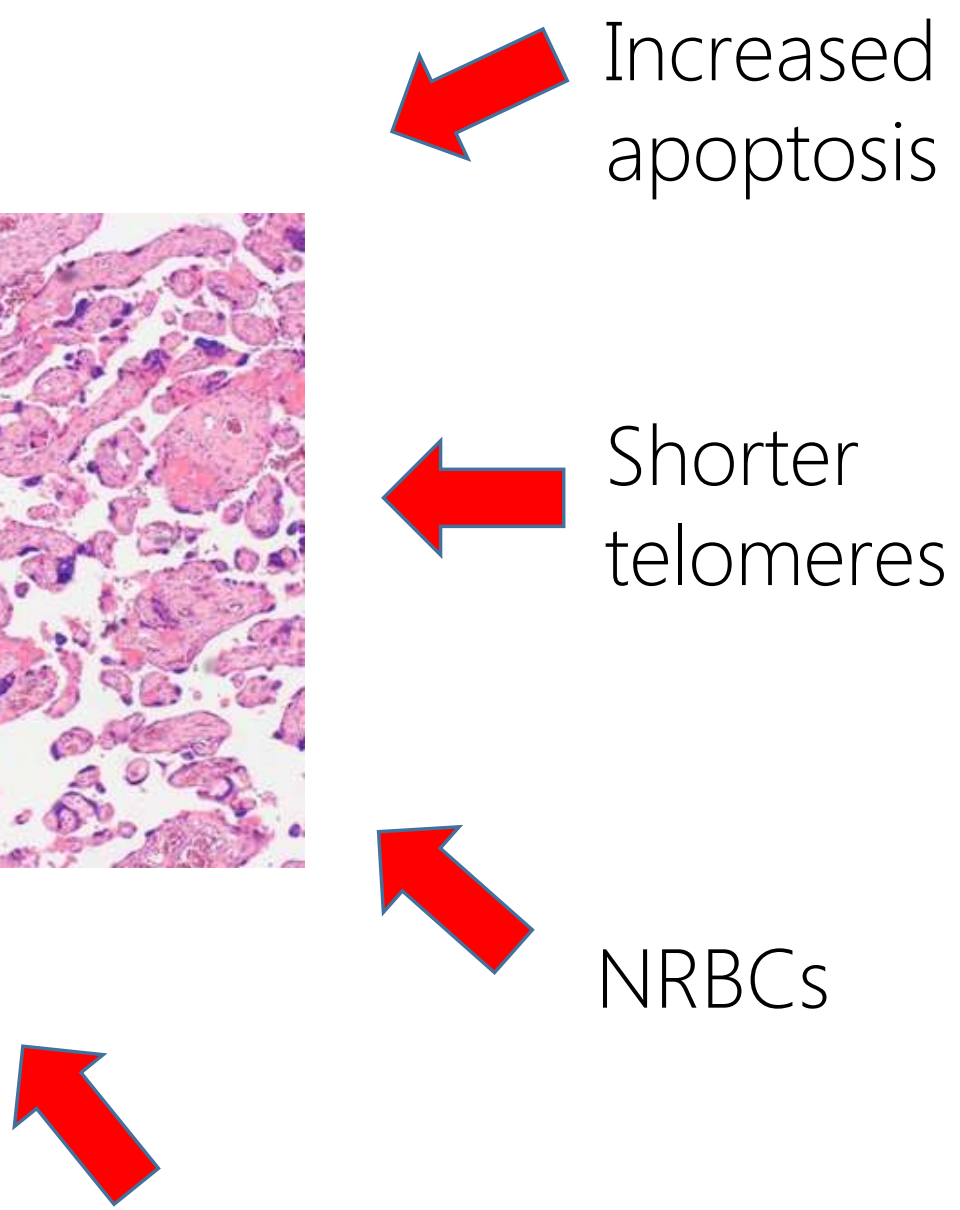

Transporter and growth factor alterations 


\section{Placenta in IUGR / SGA}

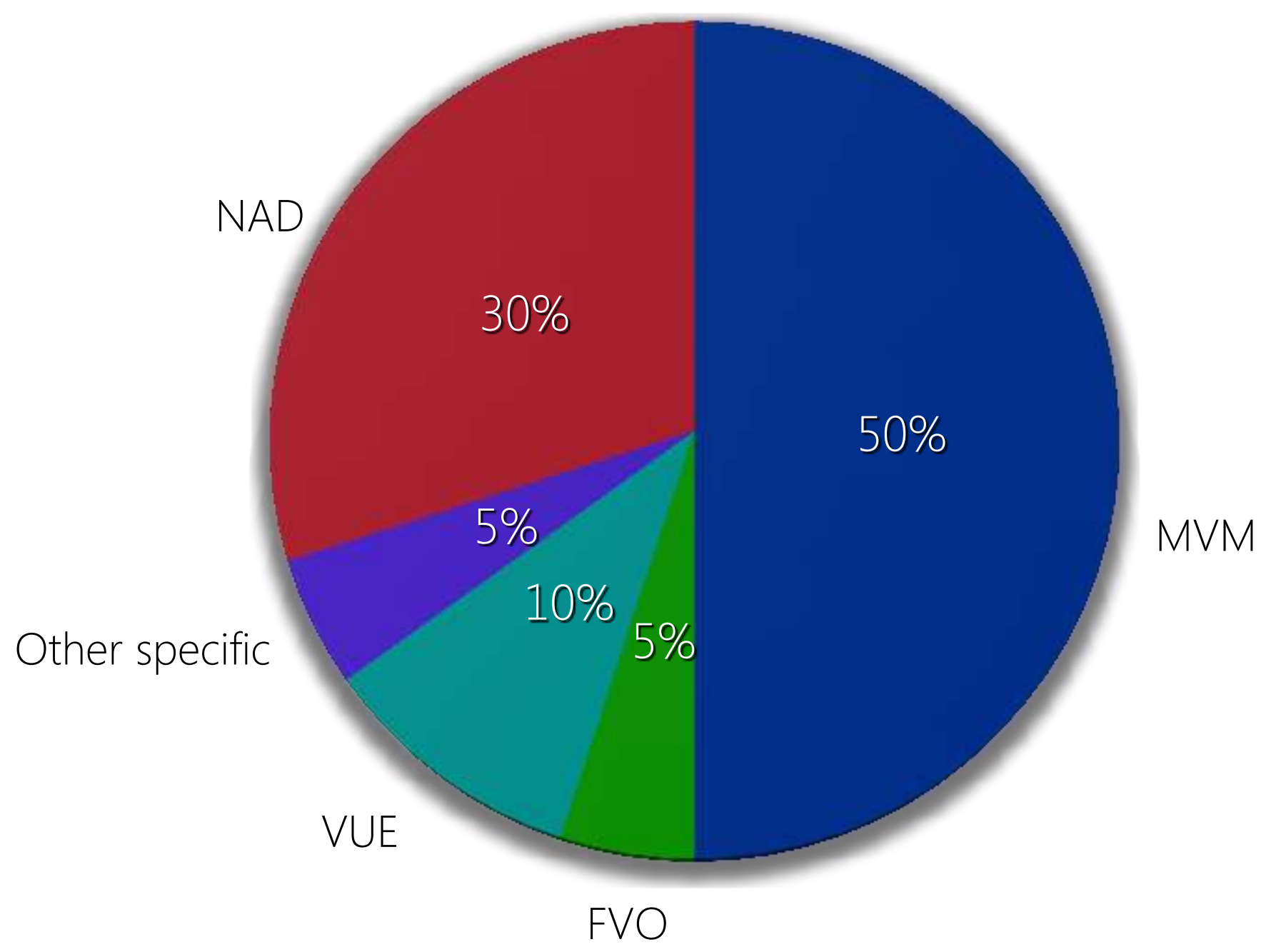

Salafia 1997, Roberst 2008, Veerbeck 2014 


\title{
Placental changes in IUGR; problems...
}

Poor correlation with Doppler or severity

(infarcts and atherosis best)

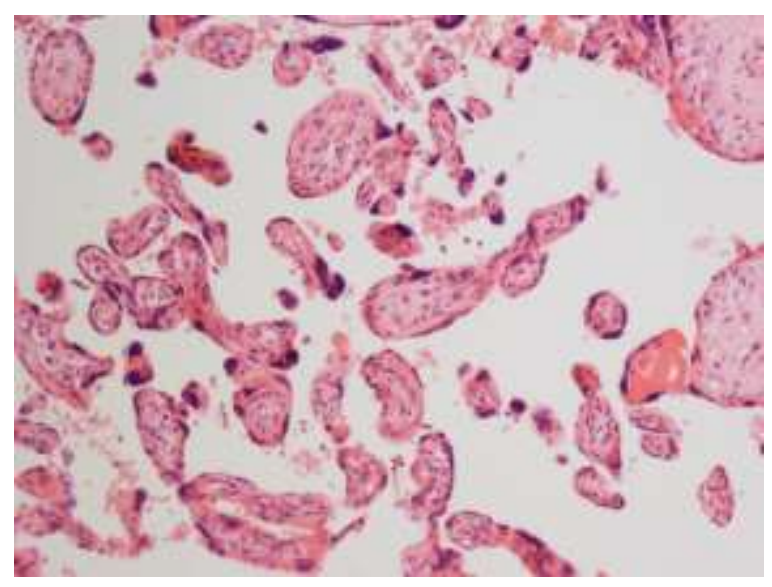

No lesion pathognomonic, many are histologically normal (approx $30-50 \%$ vs $70 \%$ controls)

\author{
Infarct $25-40$ vs $10-15 \%$ controls \\ Villitis $8-21$ vs $3-5 \%$ controls \\ Maturation/knots $90 \%$ vs ???
}




\section{Methodological issues}

-Poor clinical phenotypes

-Definition of lesions

-Interpretation of lesions

-Blinding and bias

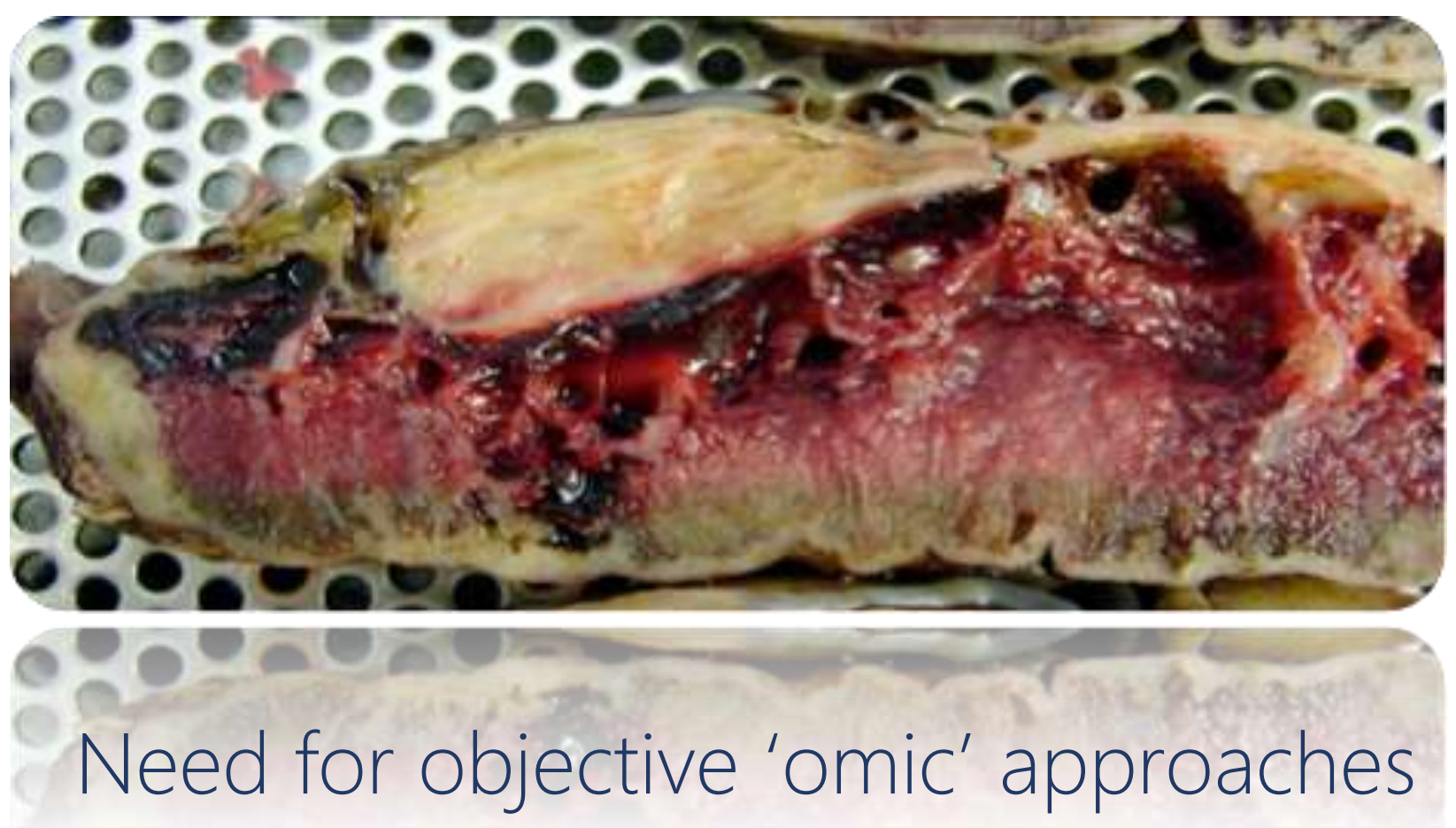


Table 2 Identified ionic species, with respective specificity and sensitivity of their diagnostic discriminant ability, obtained with ROC curve analysis

Identification type Metabolites
Label, according

to XCMS software

A

Definitive

Definitive

Definitive

Definitive

Definitive

Definitive

Definitive

Definitive

Definitive

Definitive

Putative

Definitive

Valine $\mathrm{C}_{5} \mathrm{H}_{11} \mathrm{NO}_{2}$

Isoleucine $\mathrm{C}_{6} \mathrm{H}_{13} \mathrm{NO}_{2}$

Glutamate $\mathrm{C}_{5} \mathrm{H}_{9} \mathrm{NO}_{4}$

Methionine $\mathrm{C}_{5} \mathrm{H}_{11} \mathrm{NO}_{2} \mathrm{~S}$

Dopamine $\mathrm{C}_{8} \mathrm{H}_{11} \mathrm{NO}_{2}$

Hystidine $\mathrm{C}_{6} \mathrm{H}_{9} \mathrm{~N}_{3} \mathrm{O}_{2}$

Proline $\mathrm{C}_{5} \mathrm{H}_{9} \mathrm{NO}_{2}$

\section{Phenylalanine $\mathrm{C}_{9} \mathrm{H}_{\mathbf{1 1}} \mathrm{NO}_{2}$}

Uric acid $\mathrm{C}_{5} \mathrm{H}_{4} \mathrm{~N}_{4} \mathrm{O}_{3}$

Caffeine $\mathrm{C}_{8} \mathrm{H}_{10} \mathrm{~N}_{4} \mathrm{O}_{2}$

5-Methyl-2-undecenoic acid $\mathrm{C}_{12} \mathrm{H}_{22} \mathrm{O}_{2}{ }^{\text {b }}$

Tryptophan $\mathrm{C}_{11} \mathrm{H}_{12} \mathrm{~N}_{2} \mathrm{O}_{2}$

$\stackrel{m}{0}$

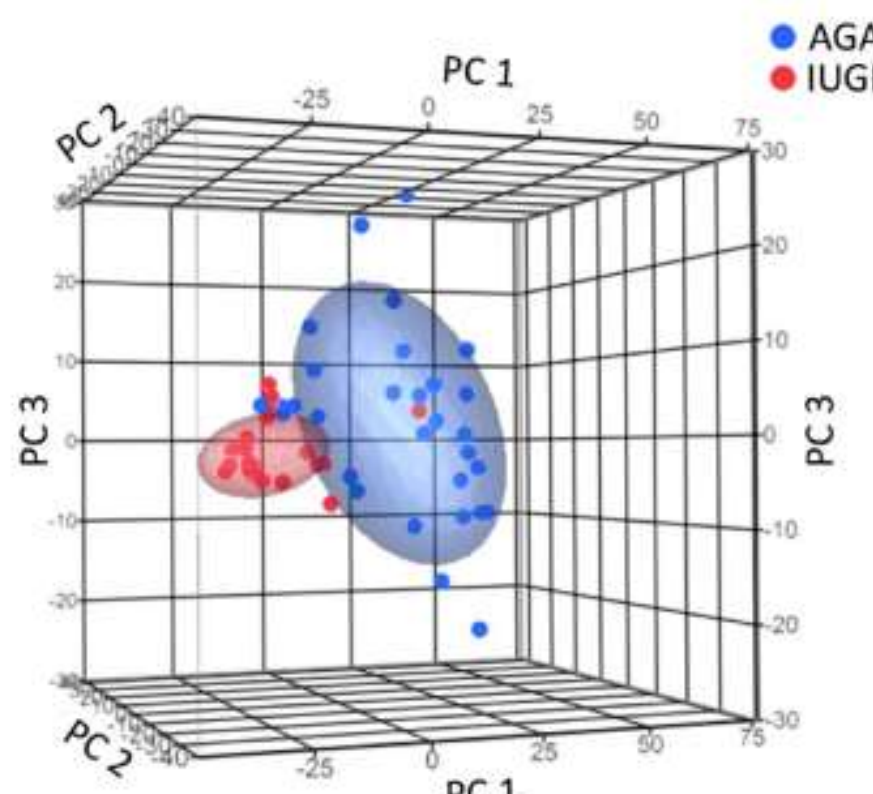

M118T89

M132T109

M148T88

M150T91

M154T113

M156T78

M116T89

M166T157

M169T71

M195T564

M199T1878

M205T219

M209T132

M229T92

M274T93

M283T1984

M287T1879

M313T768

M392T1941

M478T2012

M517T1958

M577T1978
$\mathrm{AUC}^{\mathrm{a}}$

Cut-off

abundance

0.055556

$\begin{array}{lll}0.055556 & 54,334,841 \quad 96\end{array}$

$0.055556 \quad 183,967,098 \quad 96$

$\begin{array}{lll}0.064583 & 723,357 & 85\end{array}$

$\begin{array}{lll}0.063889 & 747,089 & 96\end{array}$

$0.065278 \quad 24,027,148 \quad 81$

$\begin{array}{lll}0.0625 & 2,616,953 & 71\end{array}$

$0.054167 \quad 10,827,974 \quad 96$

$0.068056 \quad 118,841,665 \quad 89$

$0.058333 \quad 1,866,553 \quad 54$

$0.059028 \quad 4,257,749 \quad 75$

$\begin{array}{lll}0.065278 & 2,474,492 & 96\end{array}$

$0.066667 \quad 159,059,405 \quad 86$

$\mathrm{Nd} \quad \mathrm{Nd} \quad$ nd

$0.067361 \quad 1,489,723 \quad 96$

$0.060417 \quad 44,019,994 \quad 96$

$0.065278 \quad 1,035,372 \quad 86$

$0.065278 \quad 1,035,372 \quad 96$

$\mathrm{Nd} \quad \mathrm{Nd}$ nd

$\begin{array}{lll}0.063194 & 1,820,121 \quad 82\end{array}$

$0.066667 \quad 5,996,730 \quad 96$

$0.064583 \quad 14,451,441 \quad 82$

$0.061806 \quad 8,384,333 \quad 79$
Sensitivity

(\%)

69

69

91

84

96

100

69

100

97

81

81

100

nd

91

69

94

69

$\mathrm{Nd}$

97

84

100

94 


\section{Placental proteome}

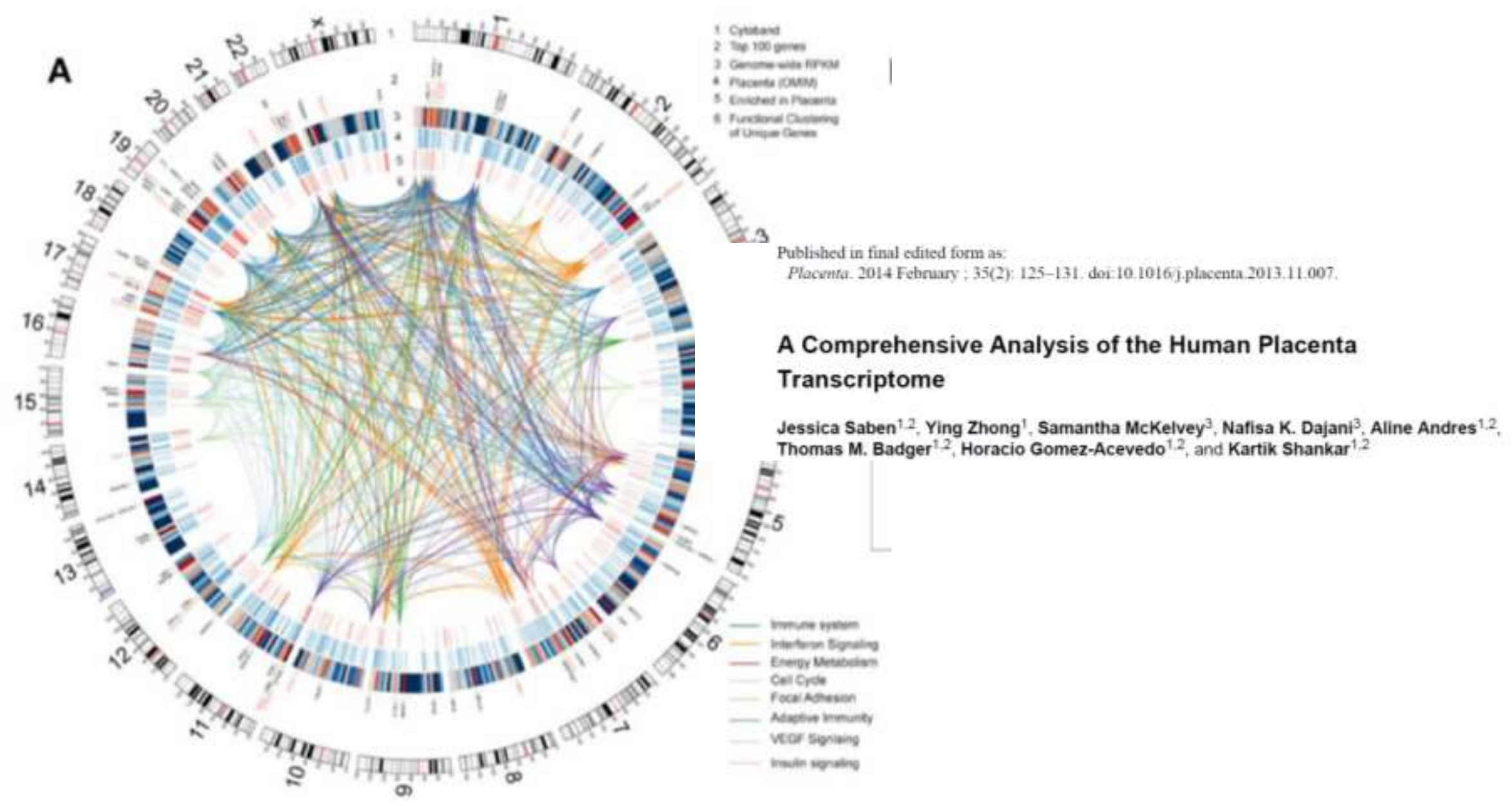

Figure 1. RNA-seq of human term placenta $(n=20)$

A) Circos diagram depicting whole-genome RNA-seq data 


\section{Proteome; normal vs PET}

groups also differed in terms of arterial blood pressure and time of birth.

\section{Collection of placental samples}

We examined the distal (maternal) portion of the placenta. The tissues were sampled immediately after delivery (sample ischemia time did not exceed $10 \mathrm{~min}$ ). Placental tissue samples were taken from the central areas close to the umbilical cord at a placental depth of $0.5 \mathrm{~cm}$. The samnles were collected from macrosconi-

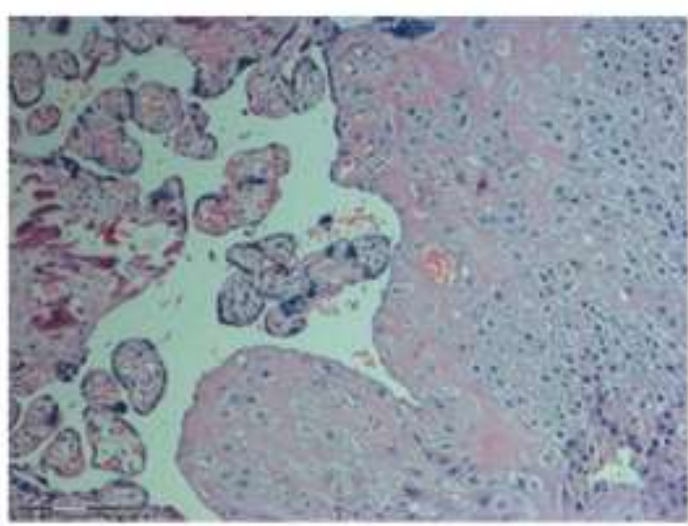

Medical University with an Institutionat Review Board (IRB) number of 2012-NFLZ-32. PE was defined as a systolic blood pressure of (or above) $150 \mathrm{mmHg}$ or diastolic blood pressure of (or above) $110 \mathrm{mmHg}$ on two occasions in six hours. The detailed patient characteristics are presented in Table S1. For each placenta sample. $0.5 \mathrm{~g}$ of tissue was dissected from the maternal side of the placentas (in the central part, exclusive of calcified area) and rinsed in $0.9 \%$ saline, then frozen in liquid nitrogen prior to use.

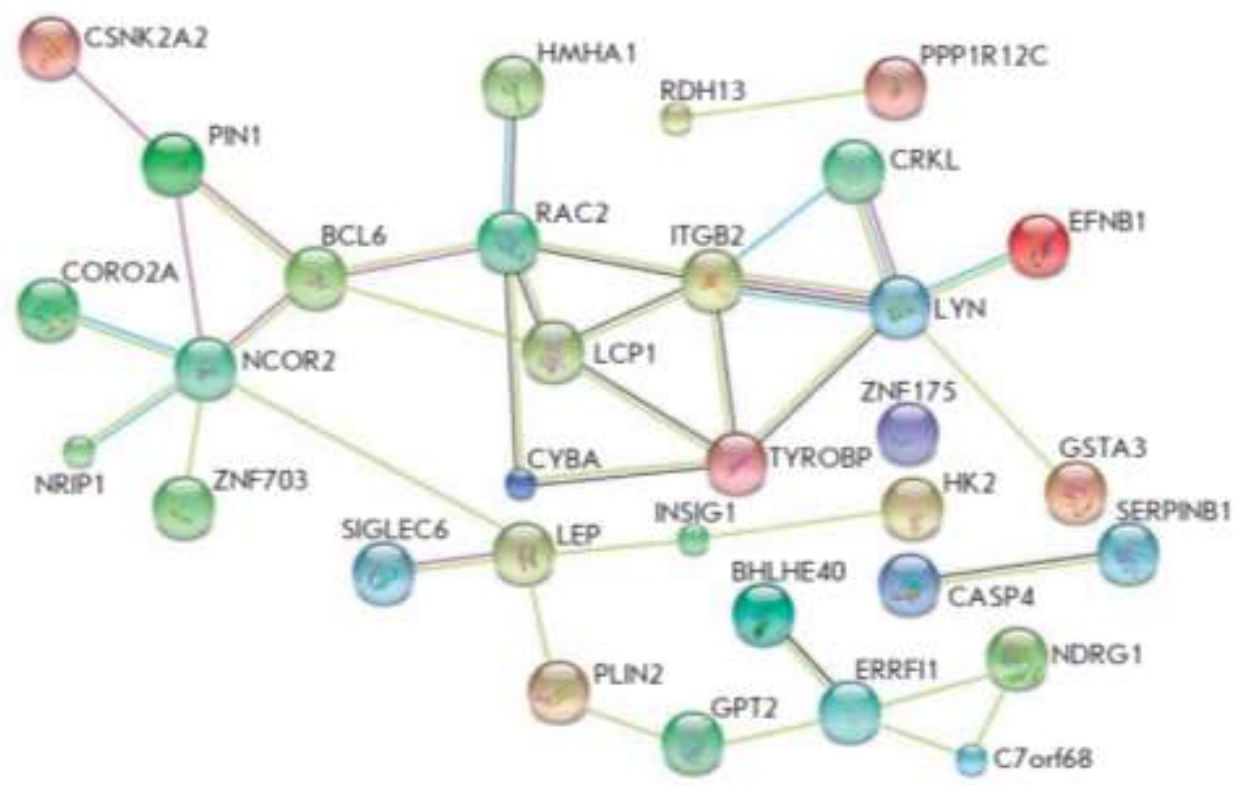


research was approved by the institutional review board of the Yonsei University Health System. We used central chorionic tissue from two paired samples (two normal and two preeclampsia tissues). A $1-\mathrm{cm}^{3}$-sized placental tissue specimen was excised from the central region of the placenta from uncomplicated and preeclampsia pregnancies following Cesarean sections. Severe preeclampsia was defined as a systolic blood pressure of at least $150 \mathrm{mmHg}$ or diastolic blood pressure of at least $110 \mathrm{mmHg}$ on two occasions $6 \mathrm{~h}$ apart, associated with clinically significant proteinuria defined as $2+$ by

A

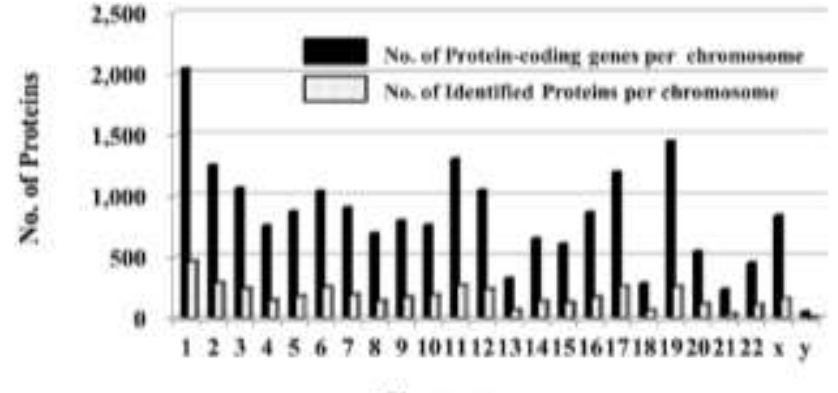

Chromosomer

B

Number of Chr-13 Proteins

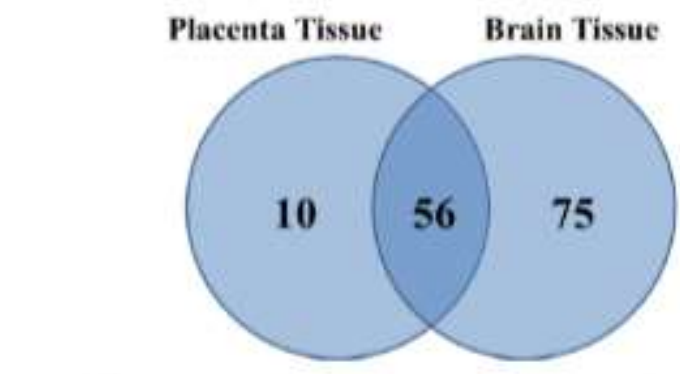

Figure 2. (A) Comparison of the number of protein-coding genes per chromosome and number of proteins identified by MS per

chromosome. (B) The number of Chr 13-specific proteins identified

\section{proteome \\ - research}

\section{Comprehensive Genome-Wide Proteomic Analysis of Human} Placental Tissue for the Chromosome-Centric Human Proteome

\section{Project}

Hyoung-Joo Lee,' Seul-Ki Jeong' Keun Na,' Min Jung Lee,' Sun Hee Lee, Jong-Sun Lim,' Hyun-Jeong Cha, Jin-Young Cho, Ja-Young Kwon, Hoguen Kim, Young Mok Park," Hail Kim," William S. Hancock," and Young-Ki Paik" 


\section{Variation in transcriptome}

ХGenome Biology

RESEARCH

Open Access

Evaluating intra- and inter-individual variation in the human placental transcriptome

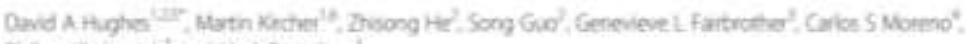
Philop Matondt' and Merk Storedung'

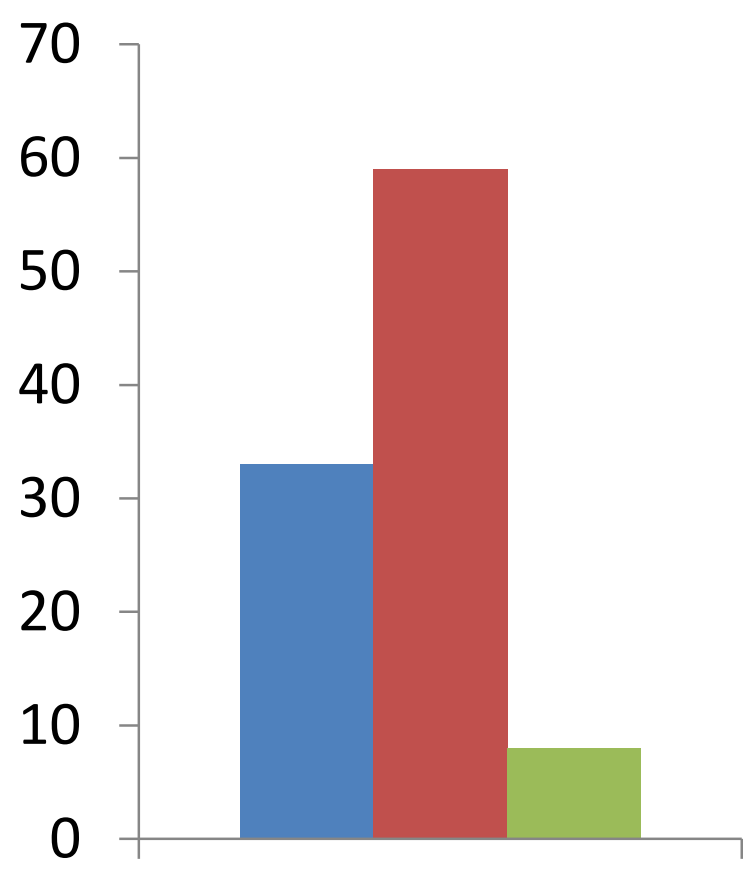

Variation

sion variation introduced in the dissection process. Specifically, tissue replicates quantify intra-individual variation in the form of (a) cell-type heterogeneity, (b) biological variation across a tissue, and (c) temporal and stochastic variation in gene expression, thus allowing for a more accurate estimation of the variation found among individuals. From three of the four-quarters of each placenta we dissected $100 \mathrm{mg}$ of centrally located villus parenchyma tissue (taking care to avoid decidua, chorion, or amnion tissue) from five non-adjacent locations, totaling 600 dissections The five dissections from each quarter were pooled, resulting in three sample replicates from each placenta. Five non-adjacent dissections were taken in an effort to homogenize the cell-type composition among samples. All dissections were carried out on a sterilized steel plate situated on top of dry

Placenta

- Individua

Groups

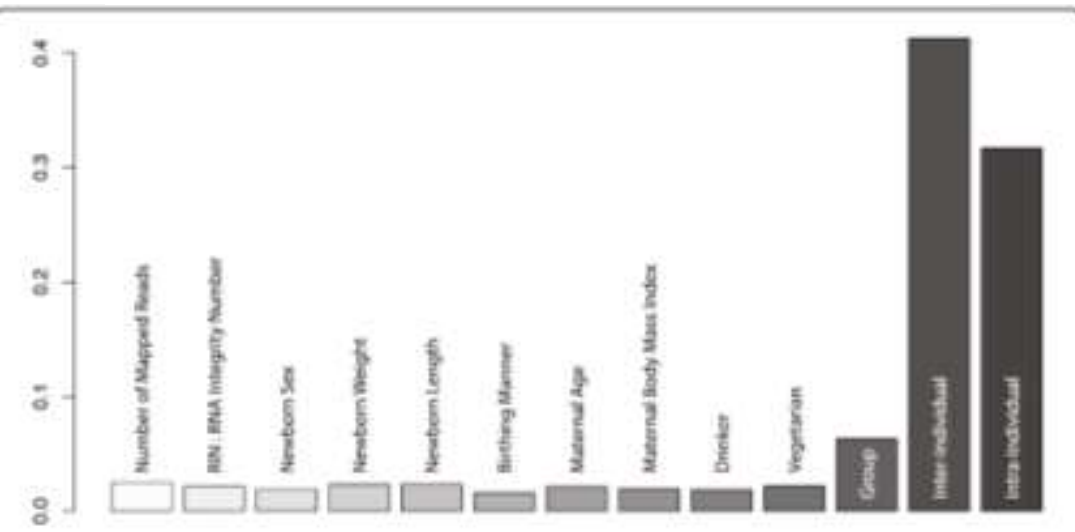

Figure 8 Apportionment bar plot. Each gene was fit to a single model accounting for 13 explanatory variables and the proportion of variation explained by each variable was estimated using the sum of squares approach. 


\section{FFPE diagnostic archives}

\section{Commentary}

Formalin-fixed paraffin-embedded tissue: The holy grail of clinical proteomics?

Valérie Broeckx't, Lise Peeters ${ }^{\dagger *}$, Evelyne Maes ${ }^{2}$, Lentel Pringels', Eddy-Tim Verjans and Bart Landuyt ${ }^{1}$

'Functional Genomics and Proteomics Unit, KU Leuven, Leuven, Belgium VITO, Mol, Belgium

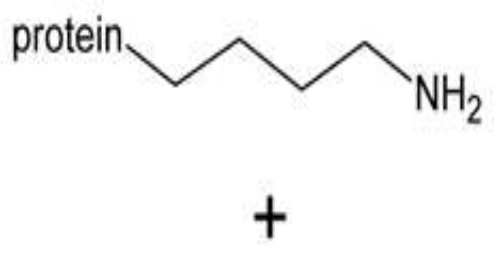

$\mathrm{HO}-\mathrm{CH}_{2}-\mathrm{OH}$<smiles>OCCCCCNCO</smiles>
$+$ $\mathrm{H}_{2} \mathrm{O}$

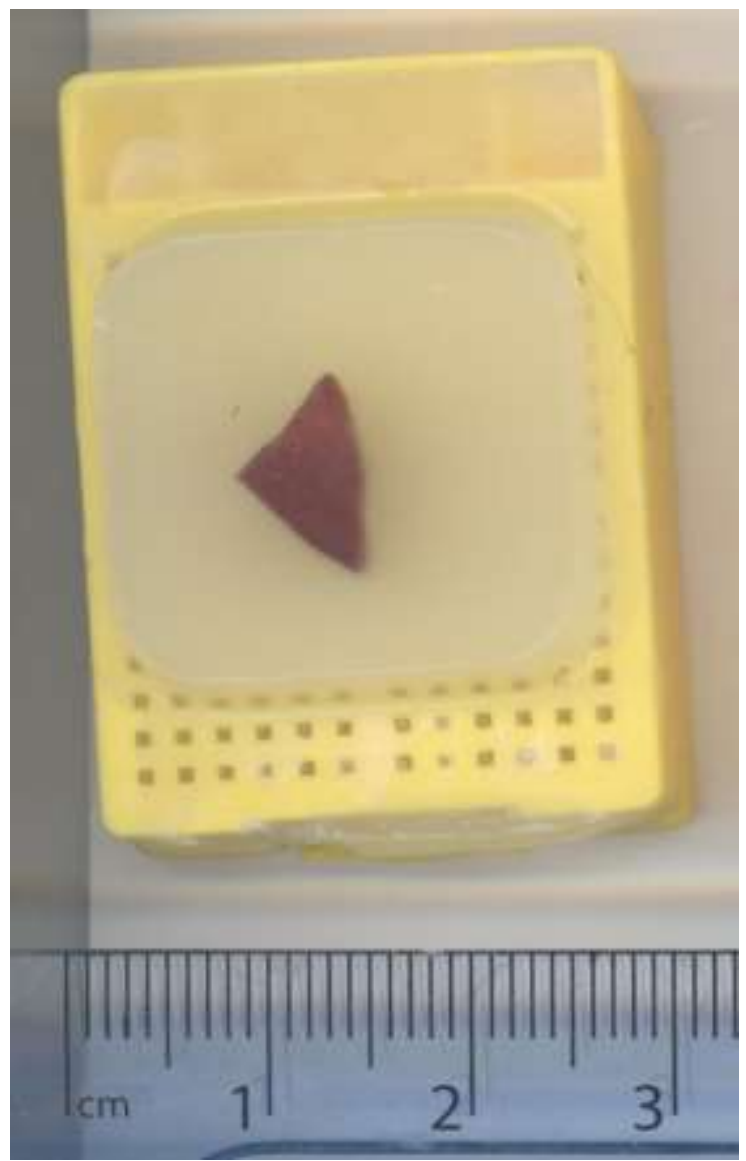

methylene glycol (aq) 


\section{Legacy}

- Well timed sample sets with serial sampling

- Methodology assessed for protocols

- No large datasets

- No clinical / social / outcome correlates

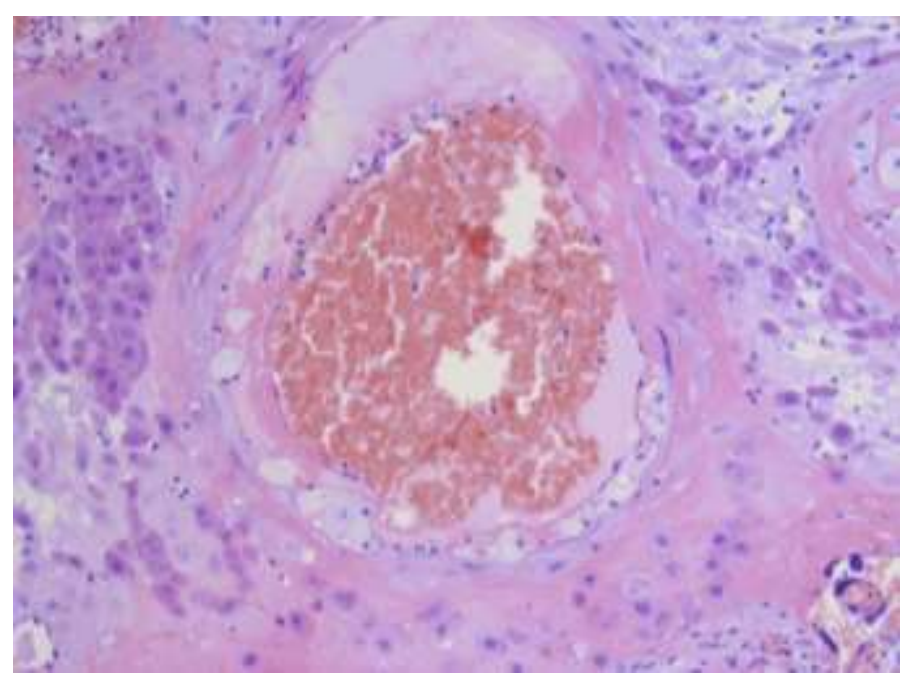




\section{"Babyomics": infection, immunity and the microbiome}

Peter Brocklehurst 
Infection and immunity in Life Study

An enhancement to Life Study

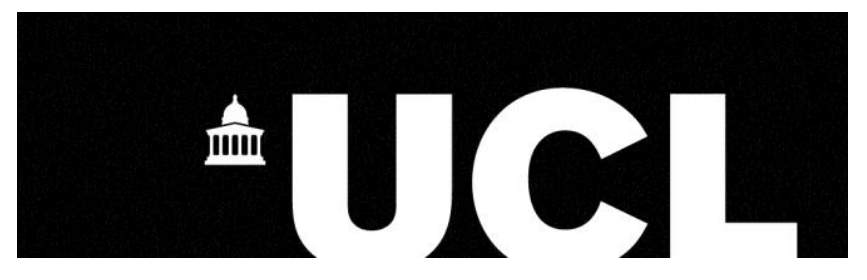

Imperial College London

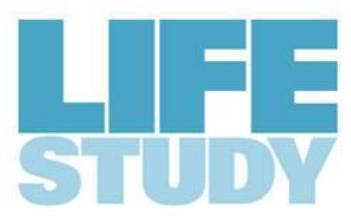

Understanding lives now and for the future

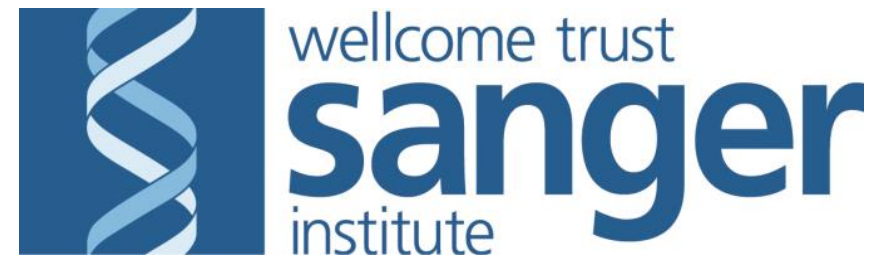

THE UNIVERSITY OF WARWICK

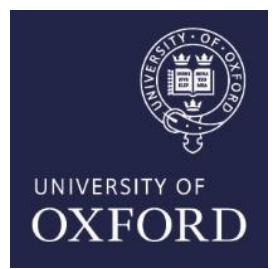


Increasing evidence that exposures in early life can have profound effects on later health and disease (Barker hypothesis, Hygiene hypothesis)

Mechanisms poorly understood

Difficult to establish sequence of events (many studies crosssectional)

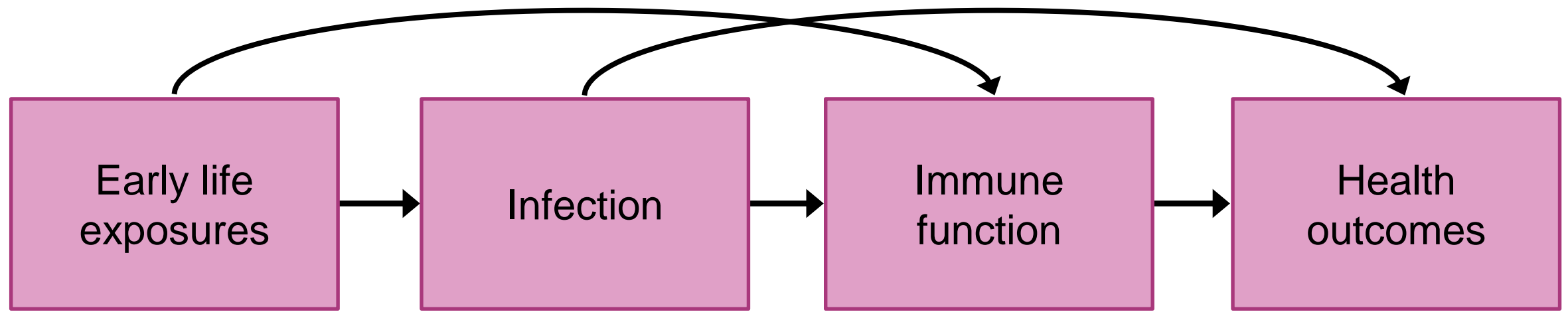




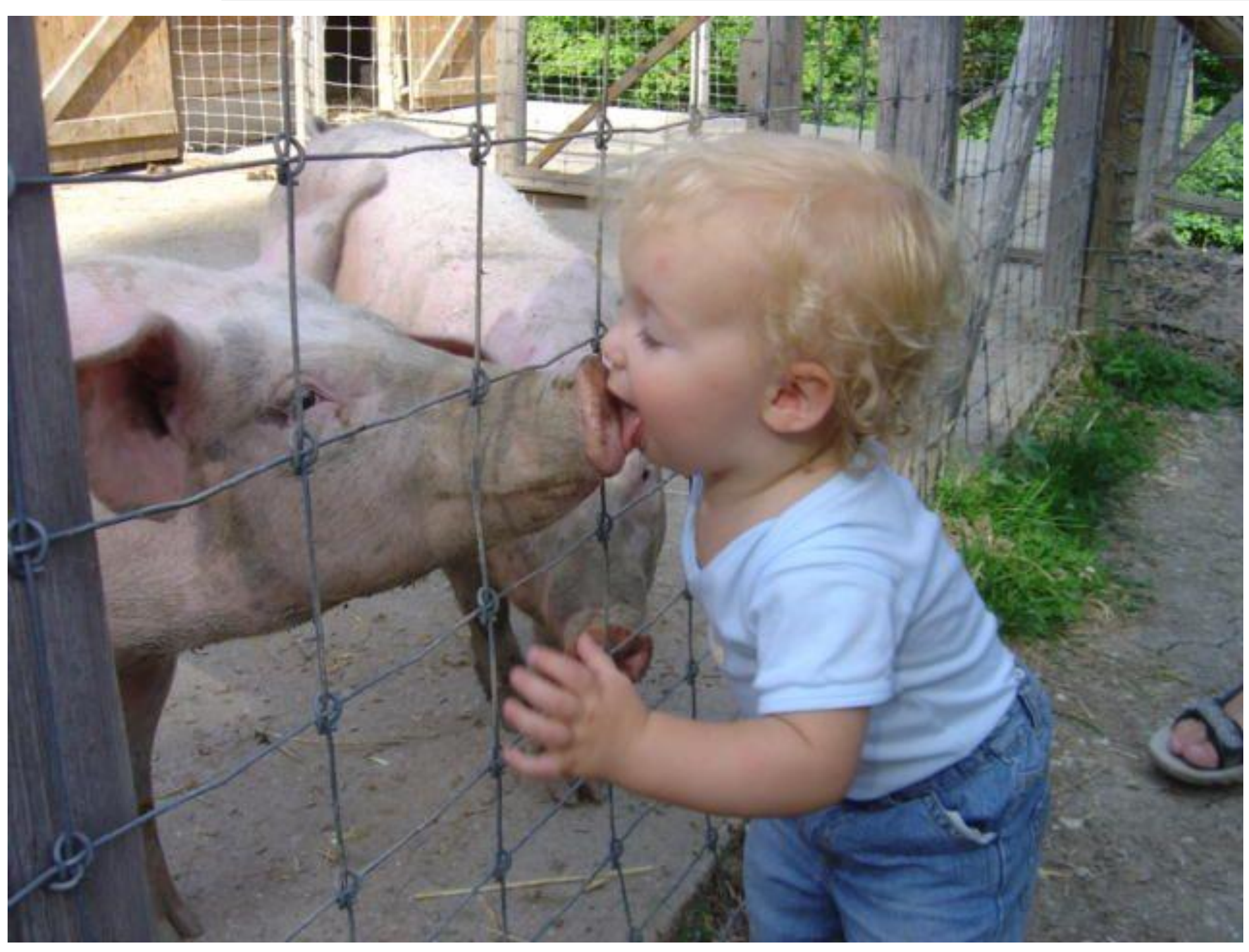


What is driving the increase in asthma, allergy, childhood diabetes...?

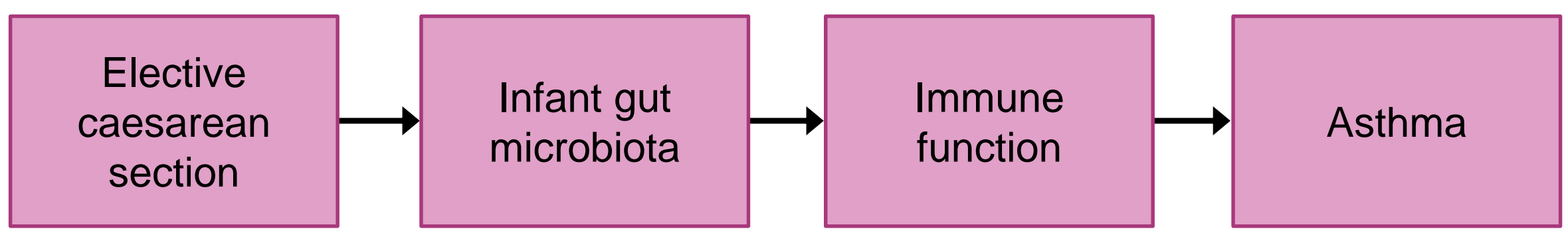


What are the long-term consequences of antibiotics in early life?

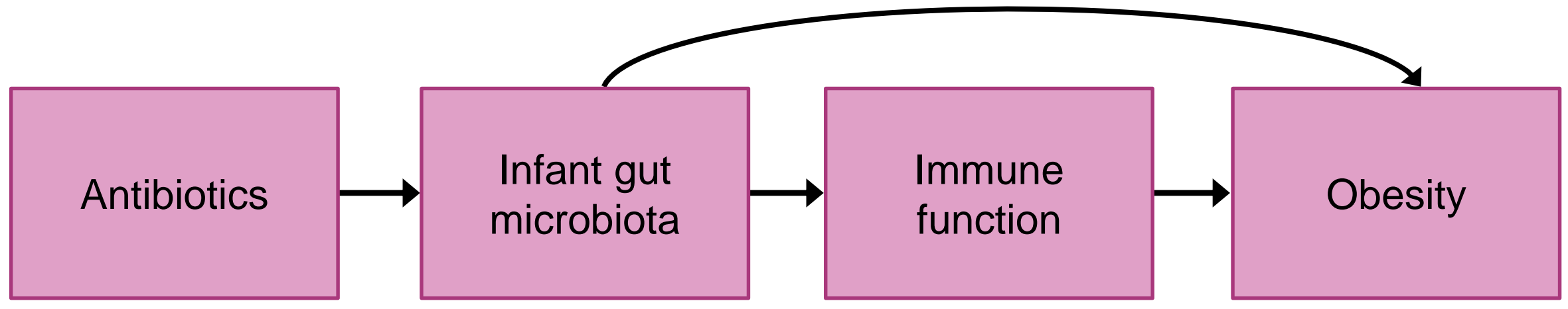




\section{Aims of enhancement}

To explore a wide range of unanswered questions relating to the impact of infection and immune development on human health

To create a 'future-proofed' and internationally unique biological archive of mother-baby paired samples 


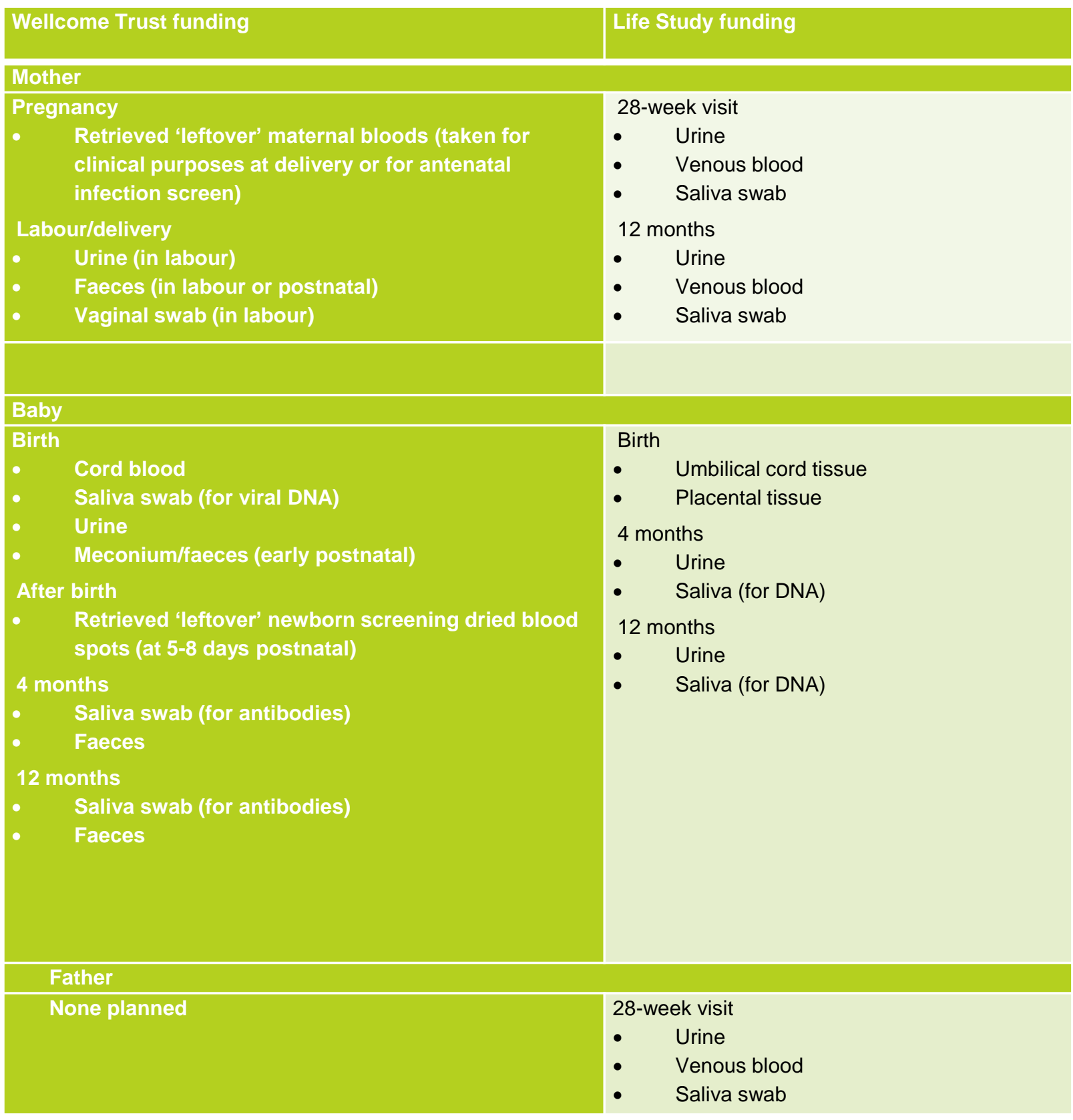

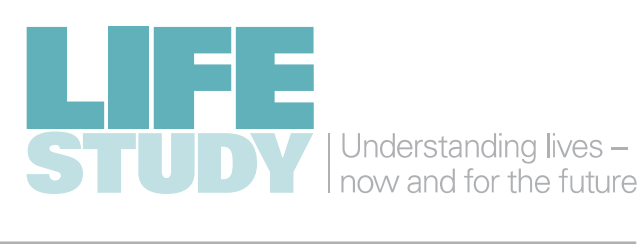


Specific objectives of the Wellcome Trust Strategic Award pilot study

To develop and pilot methodology and project infrastructure

To archive mother-baby paired samples

To produce early scientific outputs 


\section{Research questions in the Pilot}

1. Is the composition of the infant's microbiota altered by:

a) Mode of delivery (vaginal / caesarean section)?

b) Whether the mother received antibiotics in pregnancy or labour?

2. In cases of preterm rupture of membranes, does exposure of the newborn to microorganisms before birth affect the neonatal immune profile (measured in cord blood)? 
Jan 2014: First assessment centre opens followed by second later in year
Jan 2015: Remaining assessment centres

open

lerstanding lives $\checkmark$ and for the future

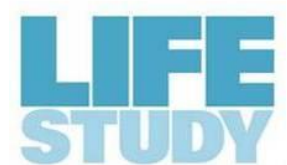

Infection \& Immunity Enhancement

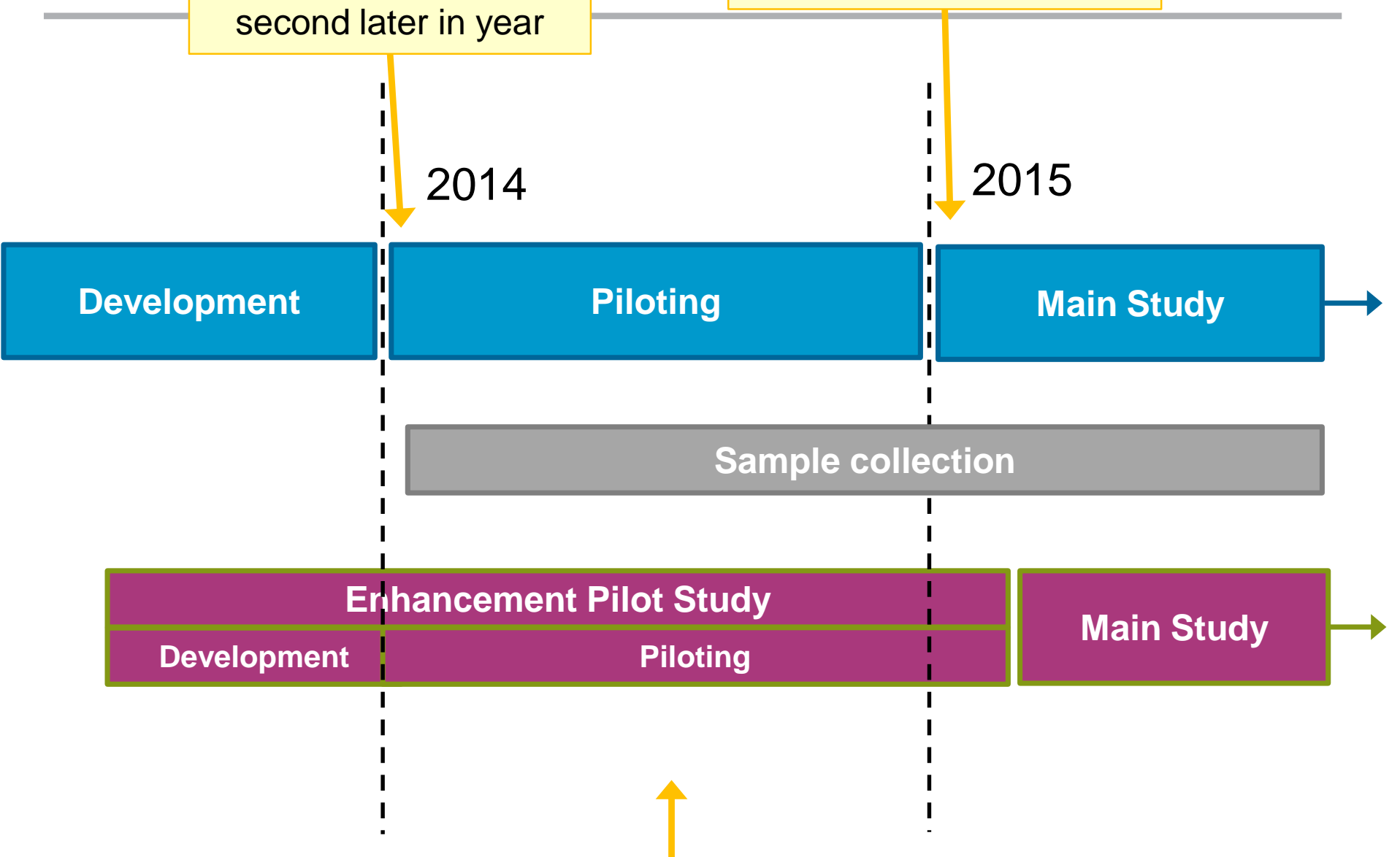

Jun 2014:

Submission of

Main

Enhancement application 


\section{Pilot Study}

$\checkmark$ UCLH pilot study experimental studies

- Optimise collection, transport and storage of cord blood and faecal samples

- Experiment with storage temp and time

- Gain experience of communicating study to participants and collecting samples

$\checkmark \mathrm{ULCH}$ acceptability questionnaire

$\checkmark$ Literature review on sample collection

$\checkmark$ Cost modelling 


\section{Acceptability of samples ( $n=113$ women)}

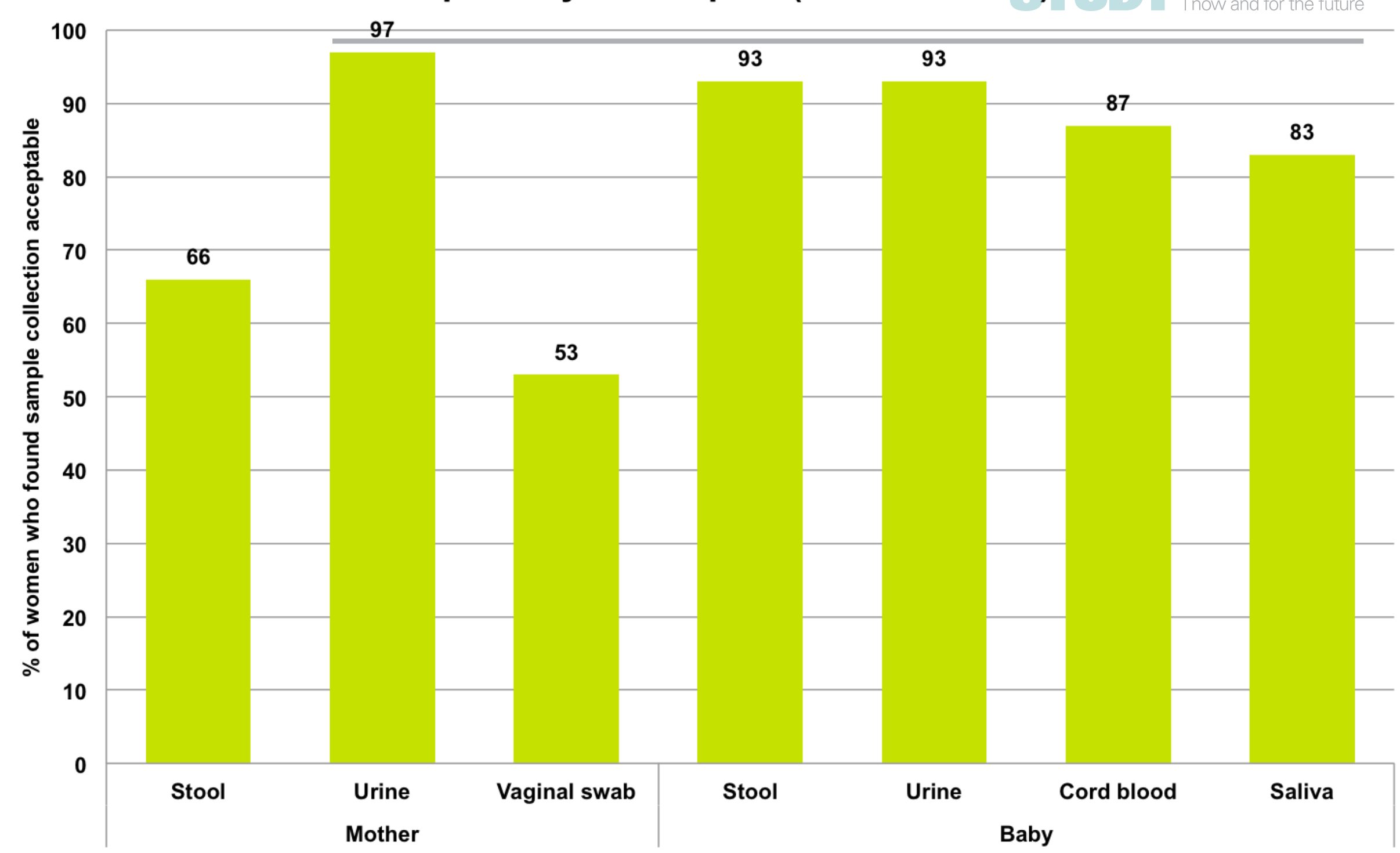


What is optimal time to sample infant?

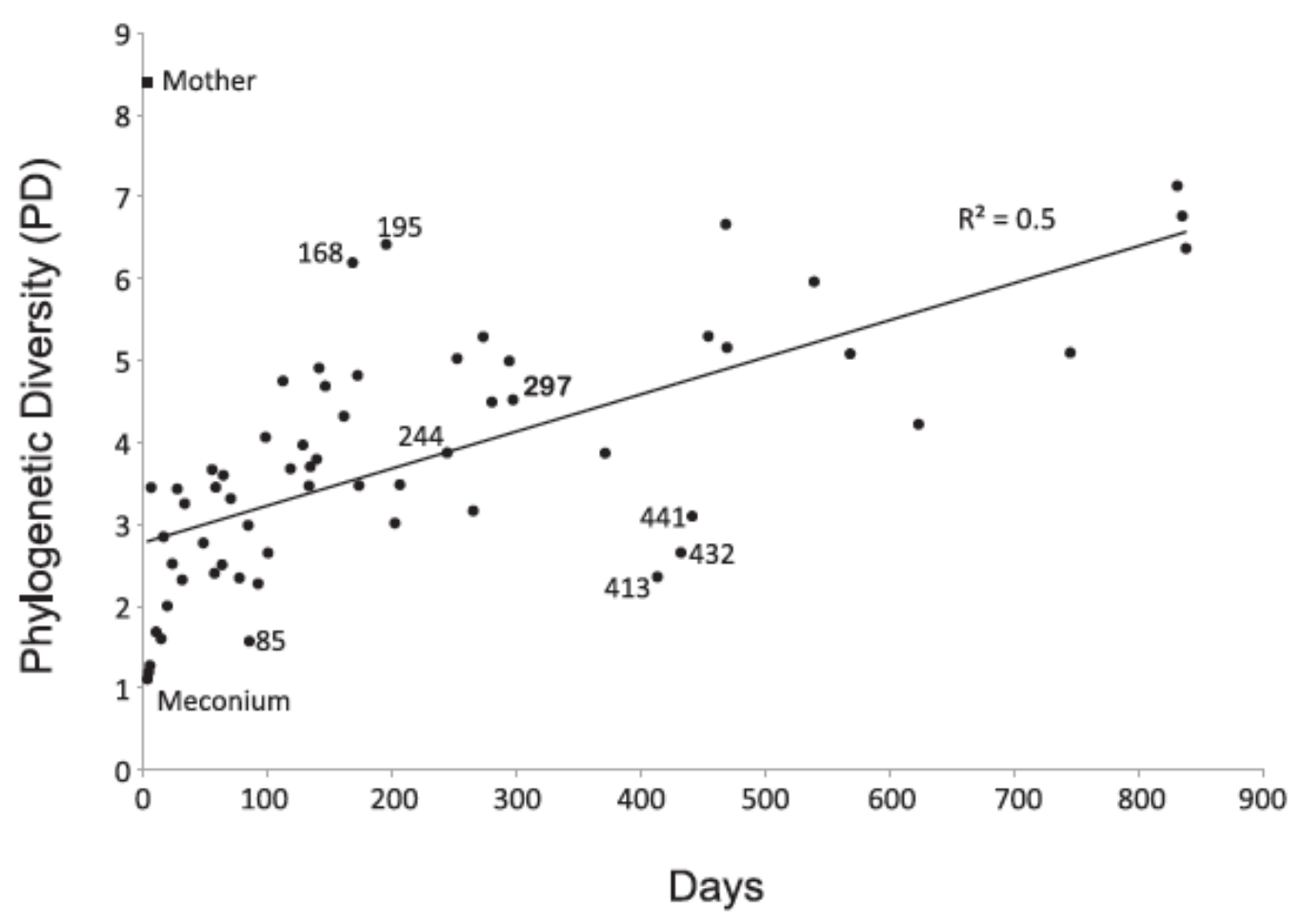

Koenig et al. 2011. PNAS.108: 4578 


\section{Baby Biosample study}

In response to poorer than anticipated recruitment to Life Study we needed to demonstrate acceptability of sample collection in labour (84 intrapartum samples collected)

Approached non-Life Study participants in labour

- Maternal faecal sample

- Cord blood

- Infant faecal sample day 7

Minimal data collection

79 women recruited so far 


\section{Babyomics Study}

In response to Life Study closing

Approach all women in labour ward/theatre

- Maternal faecal sample

- Vaginal swab

- Cord blood

- Infant faecal sample day 7

Data collection

Consent to record linkage for more extensive clinical data (from pregnancy) and for future health exposures/outcomes

REC approval 
Infection and Immunity study can continue now that Life Study has closed

Most of the initial objectives can be met with record linkage - no plans for detailed child development outcomes to be measured

Current focus

- recruitment of UHL and UCLH as participating centres

- demonstrate feasibility

- obtain funding for main study 


\section{Neuro-development in infancy:}

\section{vision, cognition and behaviour}

Hay, Smith, Johnson, Peckham, Rahi, Charman and Emond 


\section{Overview}

- Aims and achievements of the neuro-development programme in Life Study

- Opportunities for future studies 
'..the things we have to learn before we can do them, we learn by doing them"

(II.1103a33 Corpus Aristotelicum)
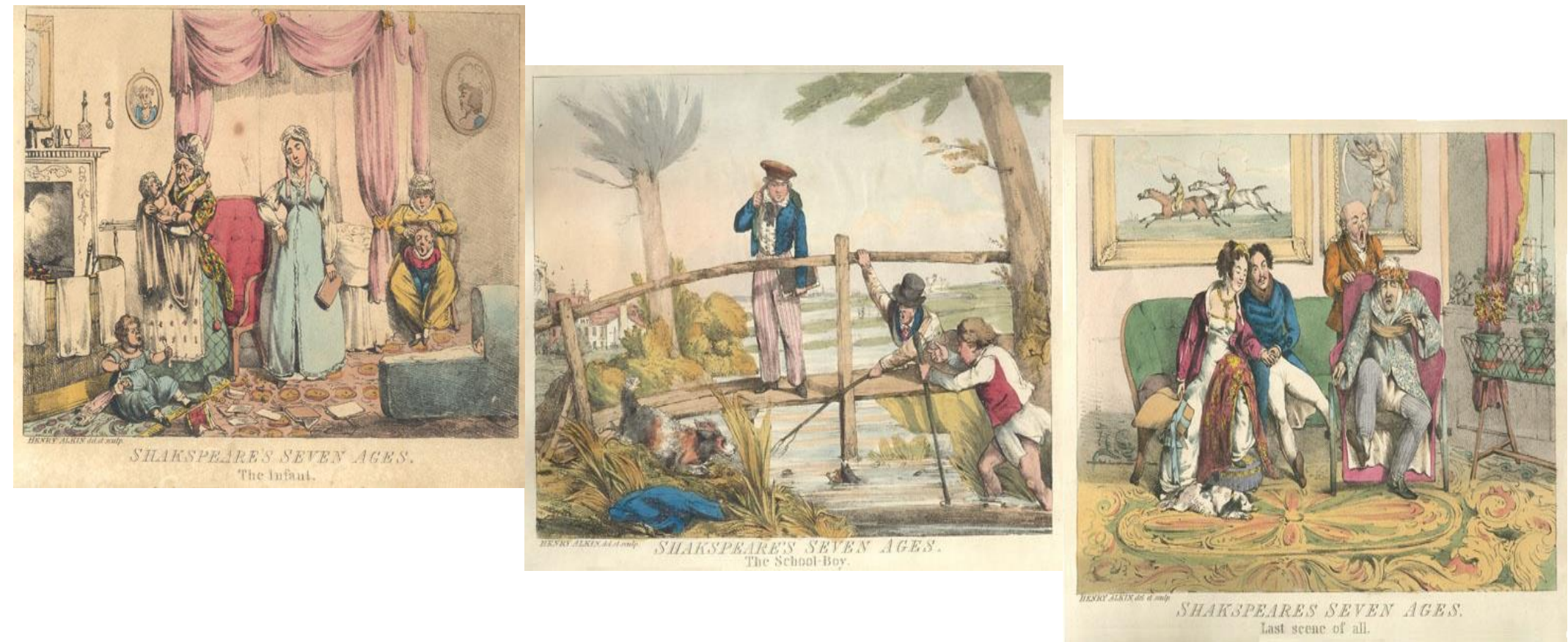

www.jamessmithnoelcollection.org

'Life can only be understood backwards, but it must be lived forward'. 
"All men by nature desire to know........ sight...., most of all the senses, makes us know and brings to light many differences between things."

(I.980a21 Corpus Aristotelicum Aristotelis Opera edidit Academia Regia Borussica, Berlin, 1831-1870). 


\section{Development of Vision}
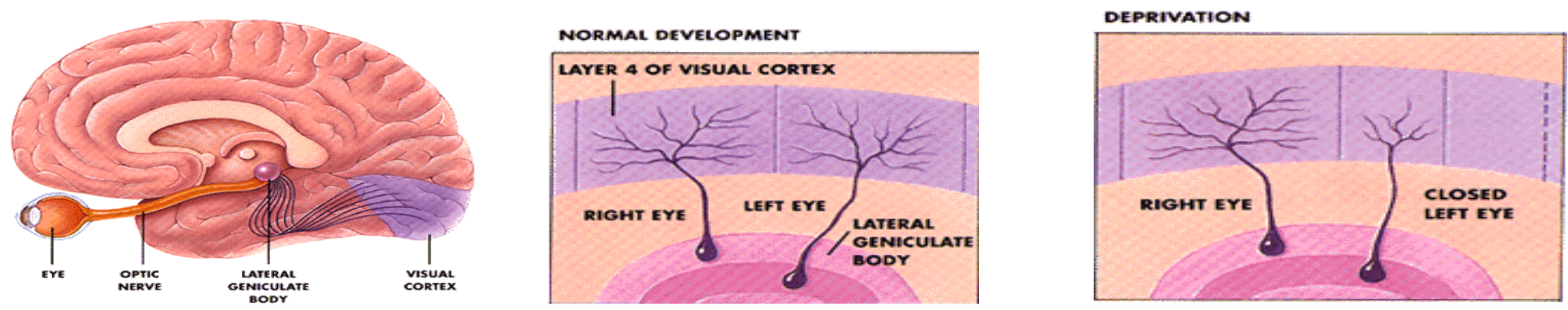

Amblyopia - Wiesel and Hubel (Nobel prize 1956)

'Critical' \& 'sensitive' periods of visual development 'time windows for intervention' - neural plasticity

Image courtesy of University of Bradford Vision Science Group
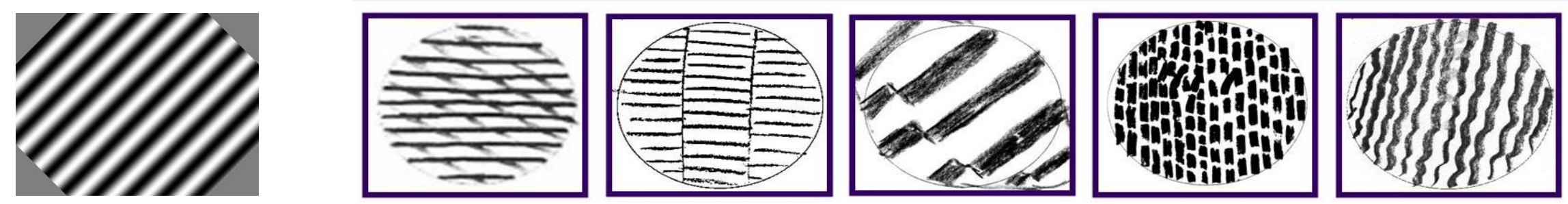


\section{Developmental course of human brain development}

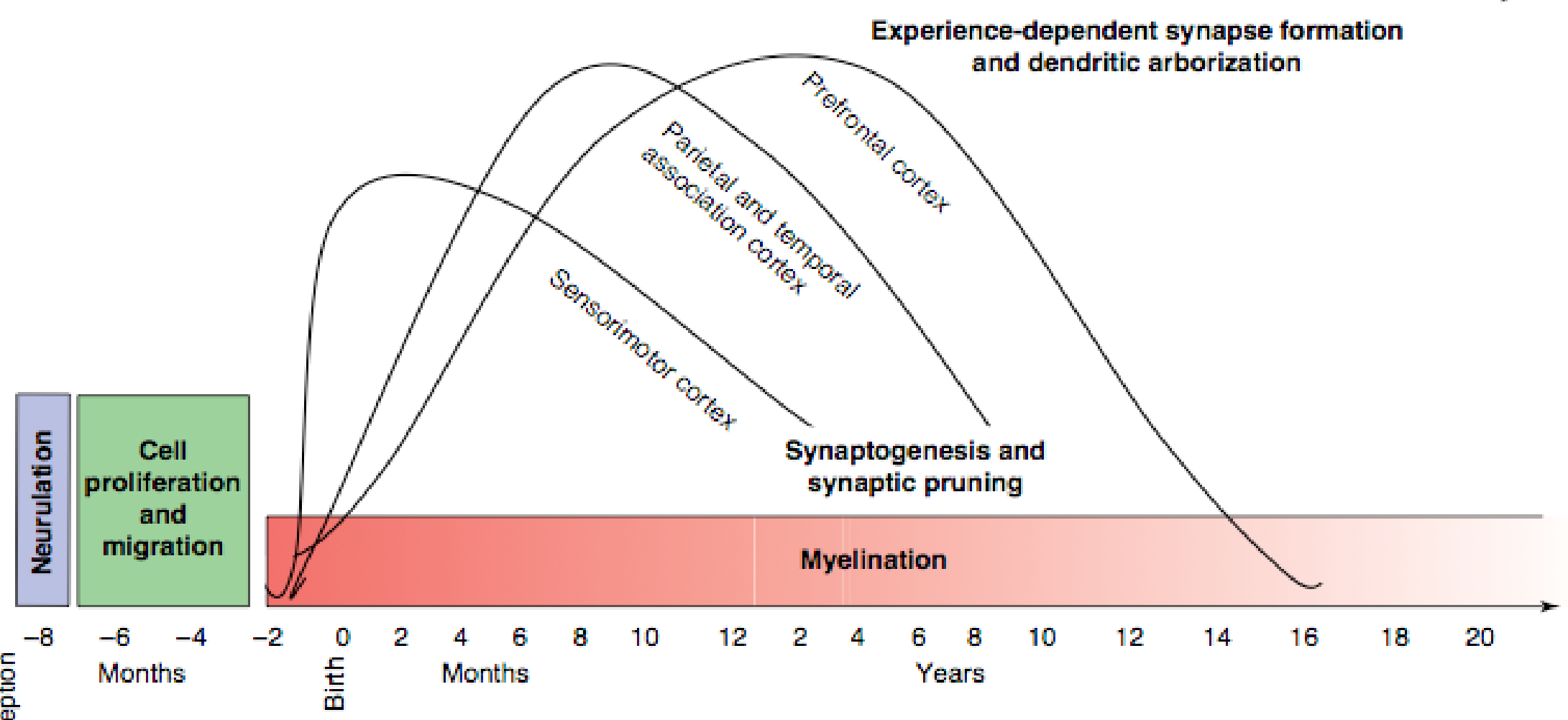

TRENDS in Cognitive Sciences 


\section{Aims}

Neurodevelopment: 'NATURE \& NURTURE'

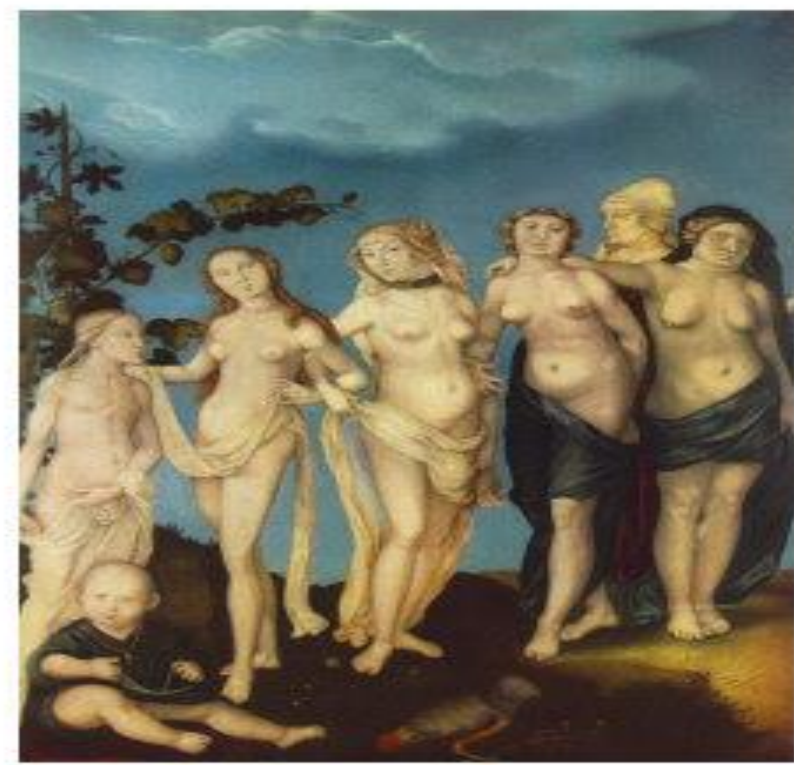

"The Seven Ages of Woman" Hans Bauldung Grien 1545 Museum der Bildenden Künste, Leipzig

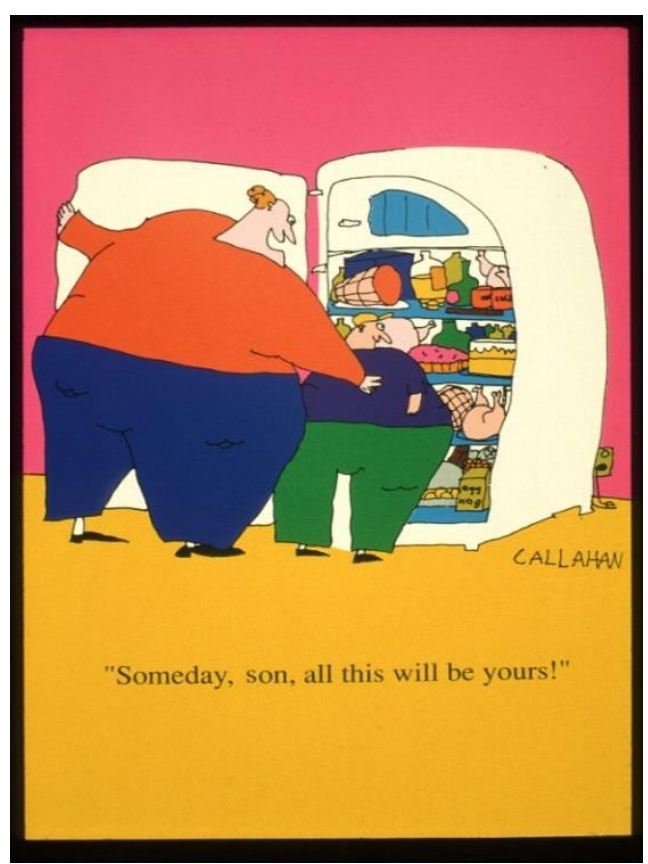

Courtesy of Prof Chris Hammond 


\section{Aims}

Understand 'normal' neuro-development and its early life influences

To identify 'predisposing factors' and 'precursor states' of

- Eyes and vision disorders (e.g. visual function/impairment, refractive error/ myopia and strabismus )

- Neuropsychiatric and neurodevelopmental disorders (e.g. autism spectrum disorder, attention deficit hyperactivity disorder, speech and language impairment)

- General cognitive, social and intellectual development (e.g. executive function, attention, memory, social cognition, and motor control) 


\section{Development of novel integrated assessment protocols}

Visual function and ophthalmic disorders

Active vision

Behaviour

In addition to data collection via questionnaire tools 


\section{Parent-infant interaction and infant's communication skills and risk for disorder}

@ 6 months

Playing with an Activity Board

Video - scored for parents' sensitivity to infants need and analysis of amount and characteristics of type of parents' speech

Cardiff Child Development Study:

Parent-Infant Interaction Helped Regulate Children's Anger and Aggression

Life Study: Opportunity to examine intergenerational issues and impact of developmental disorder 


\section{Parent-infant interaction and infants' communication skills}

and risk for disorder

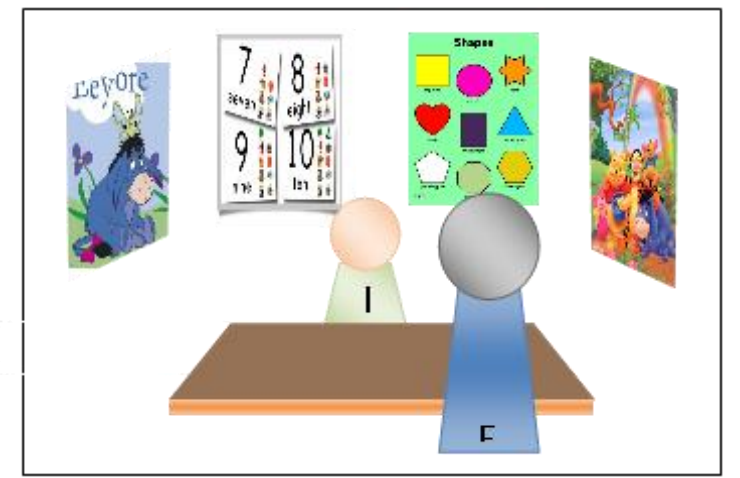

Joint Attention Task@12 Months

Does baby look where directed, check back to exchange glances and/or points things out to the researcher and parent

Cardiff Child Development Study:

Mother-Infant Interaction Fosters Joint Attention Skills and Language

Life Study: Opportunity to study the early pathway to speech and language impairments and other neurodevelopmental disorders 


\section{$\underline{\text { Infant active vision }}$}

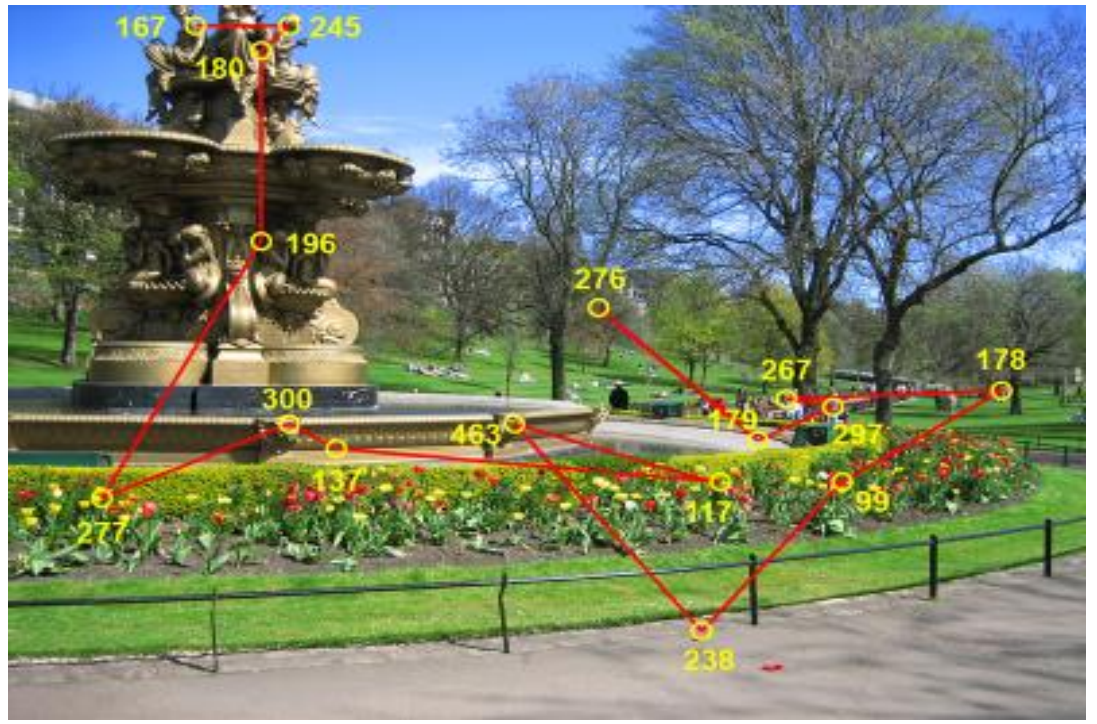

Measures of online cognition and oculomotor can be gathered during free-viewing of baby friendly images \& videos.

Attention Shifting $=$ Saccades Visual Encoding = Fixations

Focus shift $=$ Vergence Motor Control

= Smooth Pursuit, saccade targeting, fixation stability

Processing Load

$=$ Pupil dilation \& Blink rate 


\section{Example: Individual differences in infant fixations predict childhood attention and behaviour.}

\section{6 month old fixation durations}

Infant gaze behaviour predicts 3-5\% of the variance in attention traits up to $3 y r s$ later.

- Effortful Control (+), Surgency (-) and Hyperactivity-Inattention (-).

(Papageorgiou, Smith, Wu, Johnson, Kirkham, \& Ronald, Psych.Sci., 2014)

\section{Newborn Looking Behaviour}

Newborn gaze behaviour predicts $4-5 \%$ of the variance in attention traits up to $9 \mathrm{yrs}$ later!

- Effortful Control (+), Surgency (-) and Total Behavioural Difficulties (-).

(Papageorgiou, Farroni, Johnson, Smith, \& Ronald, Sci.Reps., in press) 


\section{Gaze-Contingent Paradigms}

\section{Gap/Overlap Task}

- Measures saccadic RT and $R T$ variability

- Disengagement: An executive component related to frontal development.

- Predicts childhood exec. func., educational performance \& ADHD traits.

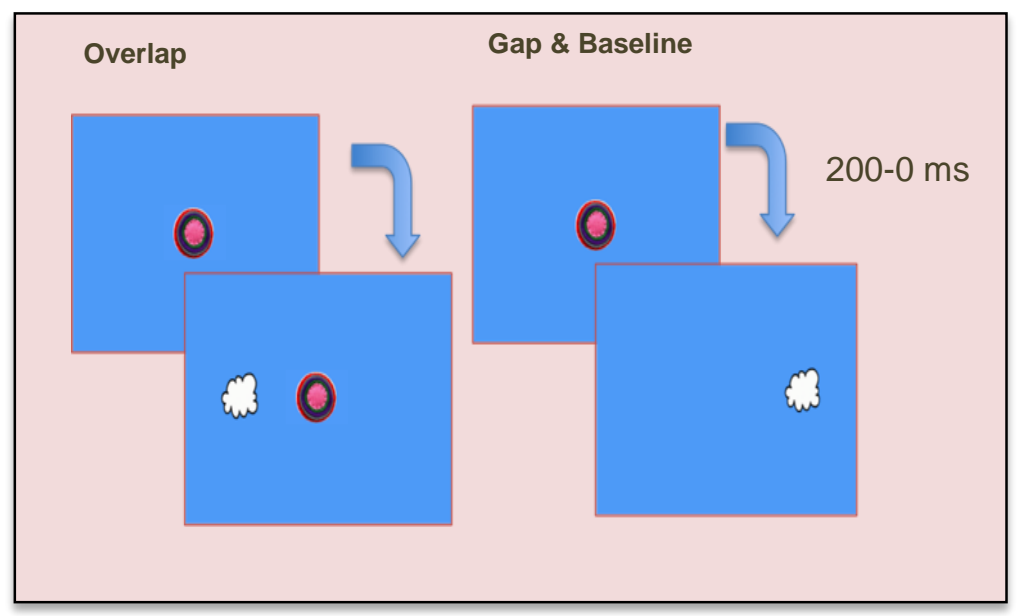

\section{Pop-Out}

- Preference for faces = Social cognition

- Visual search, saccade targeting, distractability.

- Predicts ASD \& ADHD outcome differentially and typical social development

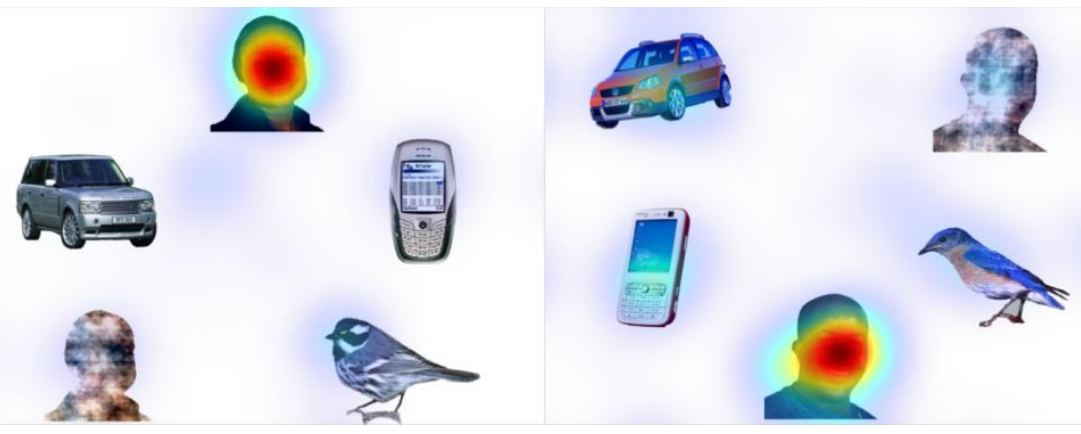




\section{Visual function - 'measure' of cognition}

Visual Acuity

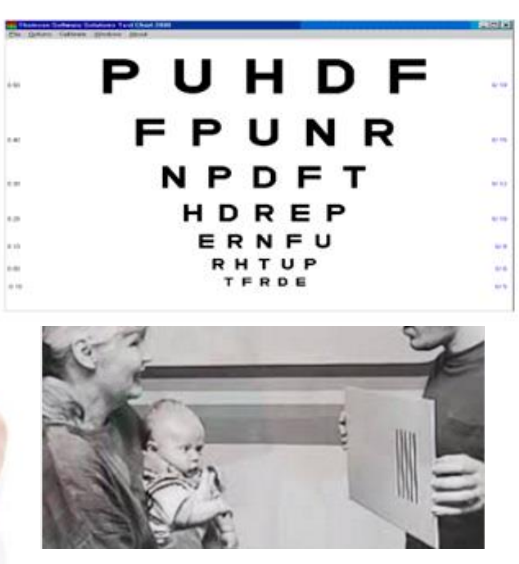

'3D' or stereovision

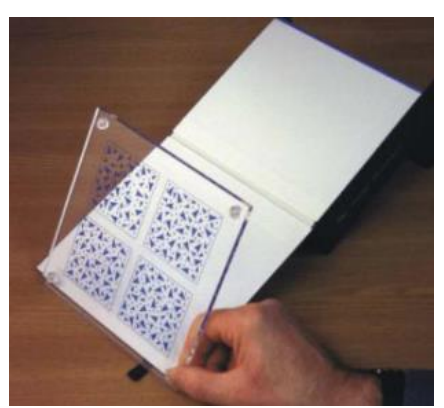




\section{Strabismus (ocular misalignment) - neurodevelopmental 'indicator'}
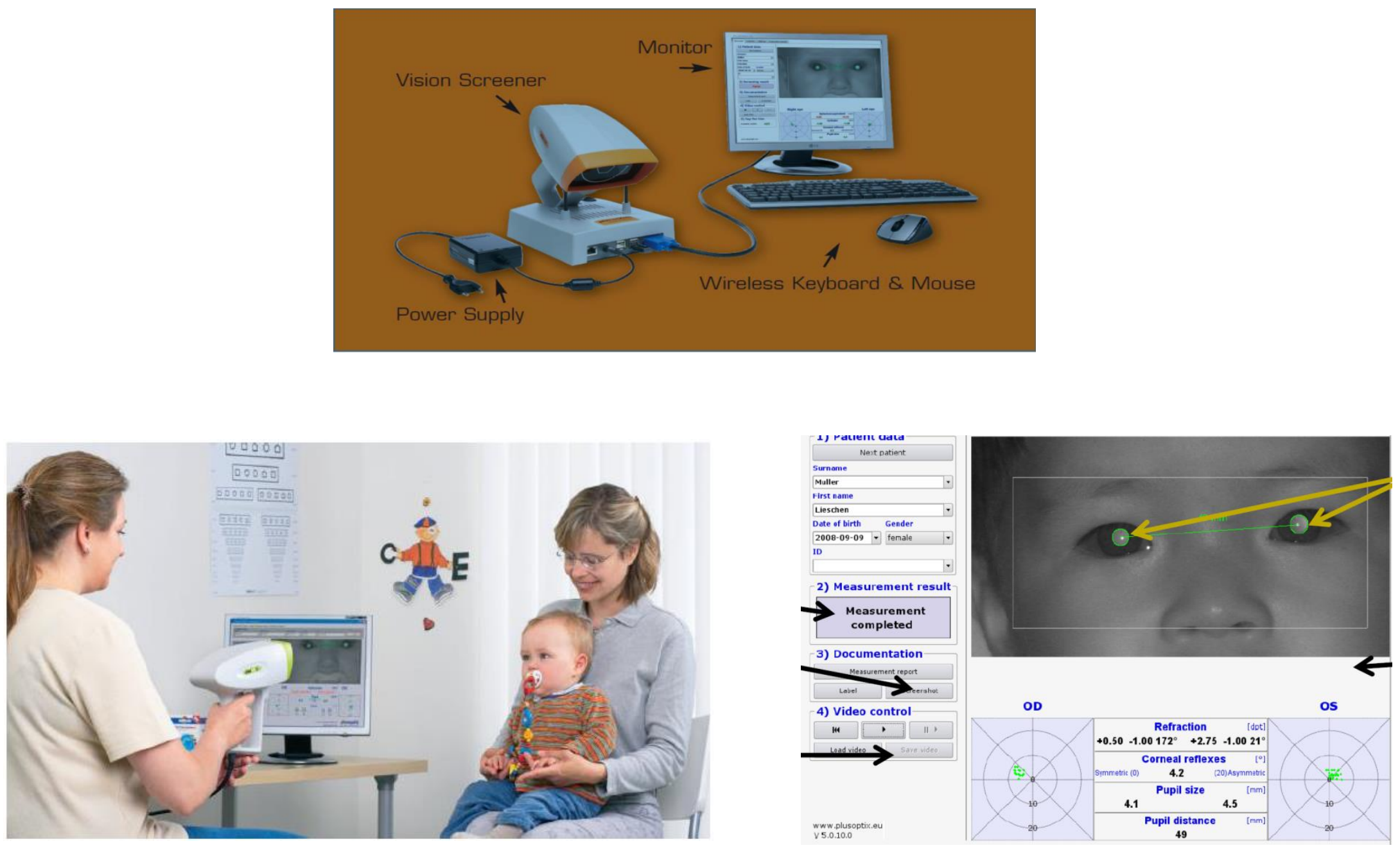


\section{Refraction}

$90 \%$ postnatal eye growth in first 2 years of life

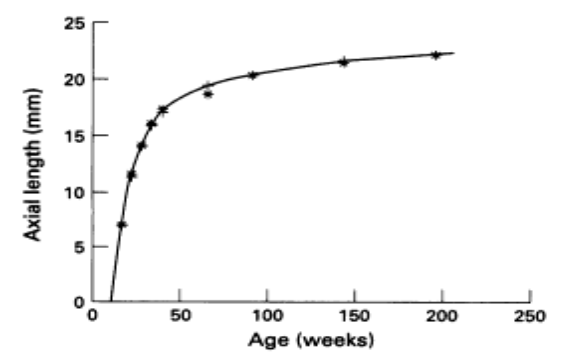

Emmetropisation (homeostatic growth to neutralise refraction)

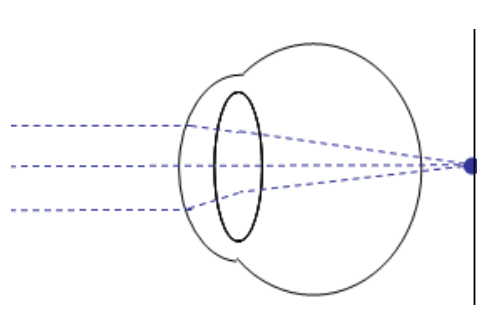

Long sighted (Hypermetropia)

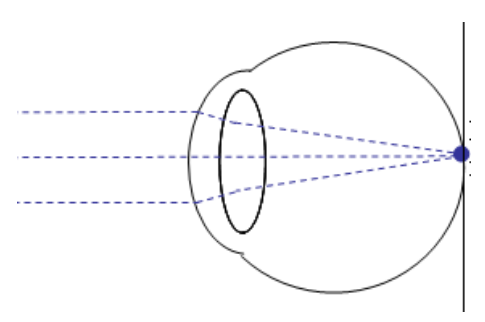

Neutral state (Emmetropia)

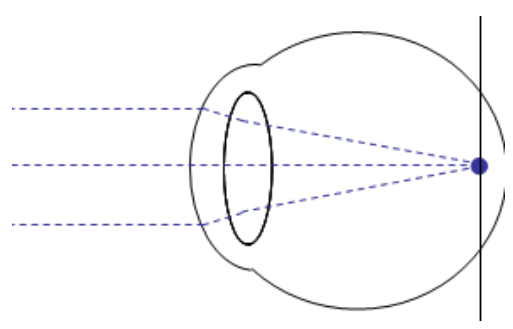

Short sighted (Myopia)

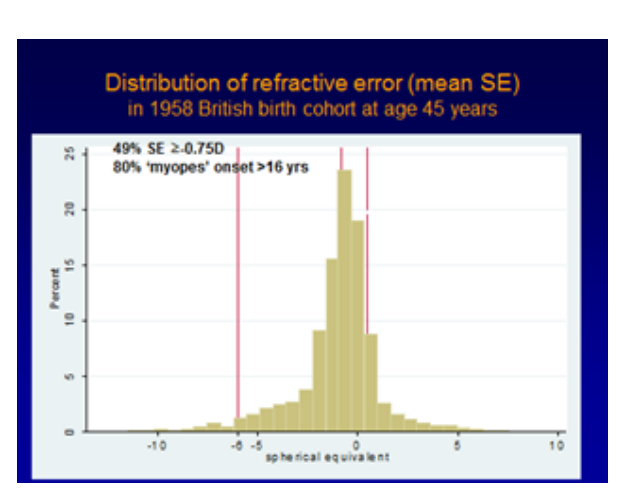

Myopia common and increasing (c. $40 \%$ in Europe, 90\% Asia)

Paradigm for complex ocular disorders interaction of genetic and environmental factors 


\section{Opportunities}

\section{Established integrated methodologies /}

protocols

ESRC Funded Studentship 2015-2019 


\section{Opportunities}

Example: 'Vision, and attention in infancy: understanding the long shadows'

Investigating:

- the development of vision in infancy

- the biological, lifestyle and broader environmental factors operating in pregnancy and early life that influence it

- the interplay between vișion and developing cognitive skills, attention and behaviour in infancy

Developing:

- quality assured methods assessment of infant vision and attention in NHS settings

Creating:

- a cohort of children with potential for follow up in later childhood and beyond eg using record linkage 